\title{
A Human Factors Perspective on Alarm System Research \& Development 2000 to 2010
}

Curt Braun John Grimes Eric Shaver

September 2011

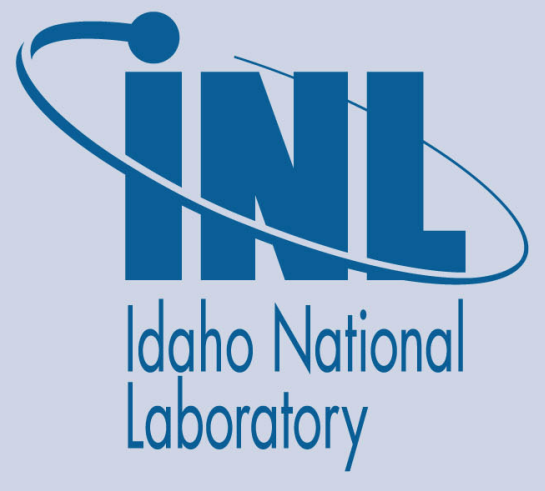

The INL is a U.S. Department of Energy National Laboratory operated by Battelle Energy Alliance 


\section{DISCLAIMER}

This work of authorship was prepared as an account of work sponsored in part by an agency of the United States Government. Neither the United States Government, nor any agency thereof, nor any of their employees makes any warranty, express or implied, or assumes any legal liability or responsibility for the accuracy, completeness, or usefulness of any information, apparatus, product, or process disclosed, or represents that its use would not infringe privately-owned rights. The United States Government retains and the publisher, by accepting the article for publication, acknowledges that the United States Government retains a nonexclusive, paid-up, irrevocable, worldwide license to publish or reproduce the published form of this manuscript, or allow others to do so, for United States Government purposes.

This research was carried out by Idaho National Laboratory (INL). INL is a multiprogram laboratory operated by Battelle Energy Alliance LLC, for the United States Department of Energy under Contract DE-AC07-05ID14517. 


\title{
A Human Factors Perspective on Alarm System Research \& Development 2000 to 2010
}

\author{
Contributors: \\ Curt Braun, John Grimes, Eric Shaver \\ Benchmark Research \& Safety, Inc. \\ Presented to: \\ Ronald Boring (Principal Investigator) \\ Idaho National Laboratory
}

September 2011

\begin{abstract}
Idaho National Laboratory Nuclear Safety and Regulatory Research Idaho Falls, Idaho 83415
\end{abstract}

http://www.inl.gov

Prepared for the

U.S. Department of Energy

Office of Nuclear Energy

Under DOE Idaho Operations Office

Contract DE-AC07-05ID14517 

Benchmark Research \& Safety, Inc.

A Human Factors Perspective on

Alarm System Research \&

Development 2000 to 2010

March 2011

Curt Braun, PhD., John Grimes, MS, Eric Shaver, PhD. 


\section{Table of Contents}

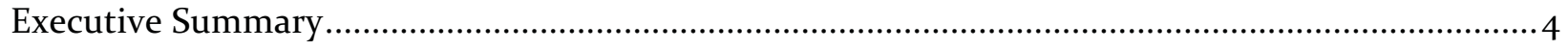

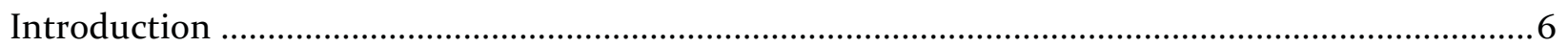

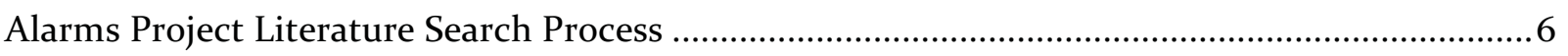

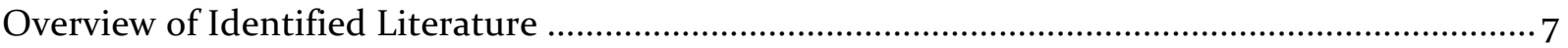

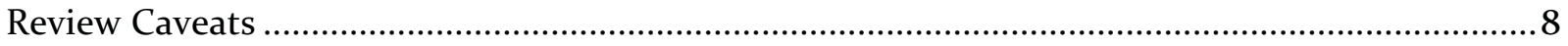

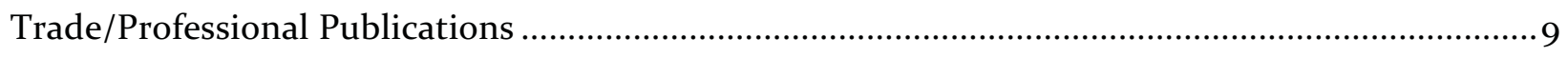

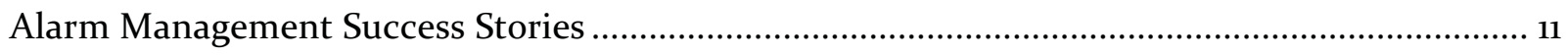

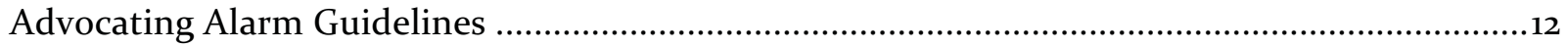

Alarm Management Missteps..........................................................................................................

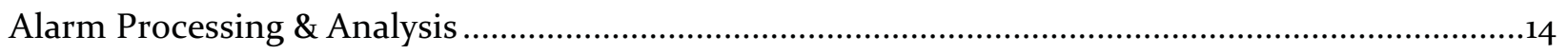

Empirical Research on Alarm Processing Methods ....................................................................15

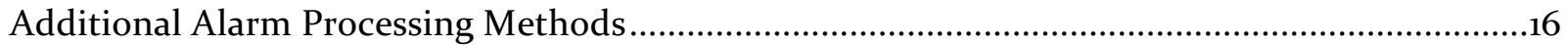

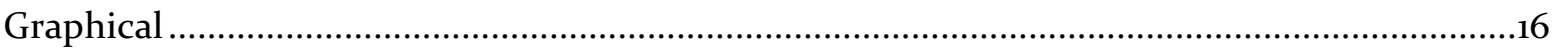

Proposed Alarm Processing Methods ...............................................................................18

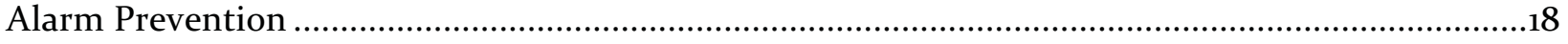

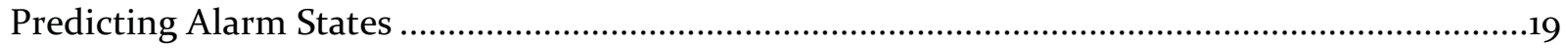

Alarm Prevention Via Multivariate Representation ...............................................................20

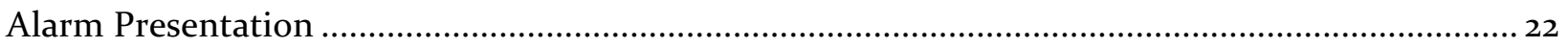

Alarm Presentation Methods Compared...................................................................................... 22

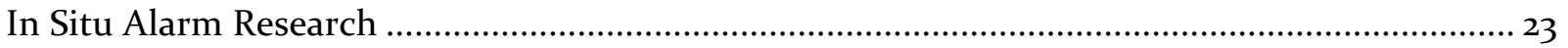

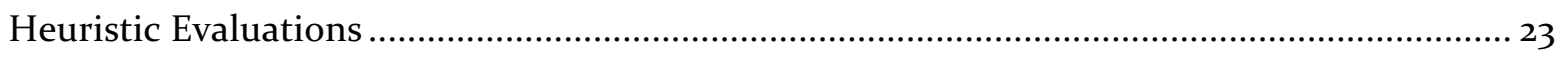

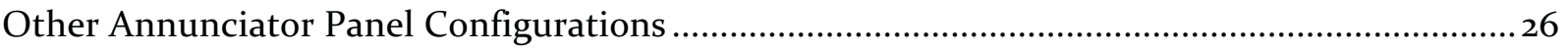

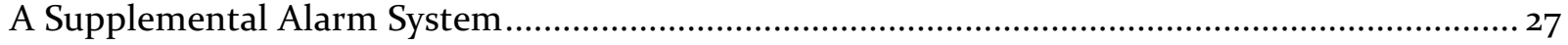

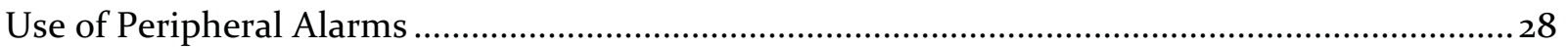

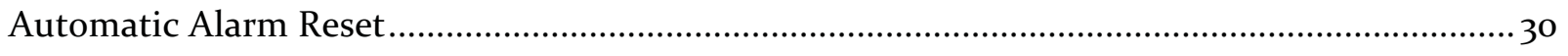

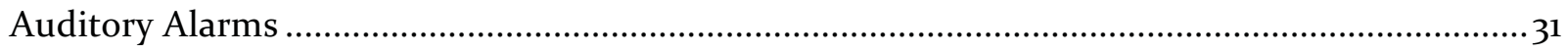

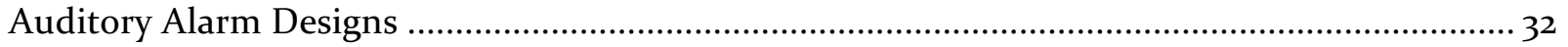

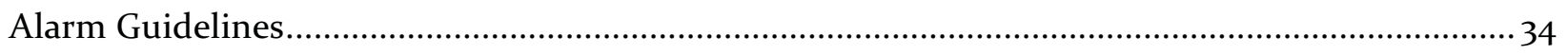

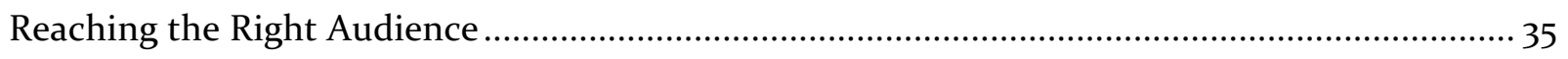

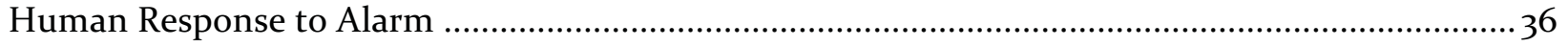

Signal Detection, Workload \& False Alarms ........................................................................... 37

2 Executive Summary | Benchmark Research \& Safety, Inc. 
False Alarms in Aviation \& Maritime Applications .............................................................. 39

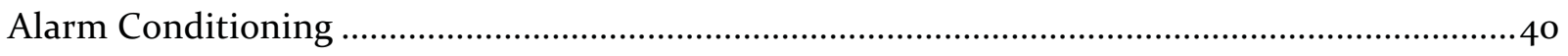

Human operators in a complex, multi-alarm environment.................................................. 43

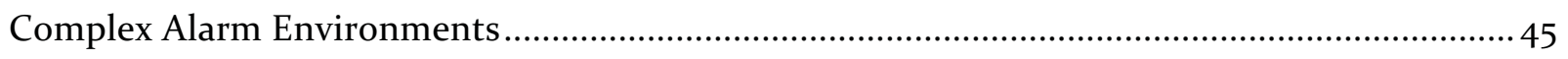

Alarm Rates and Alarm Information …..............................................................................

Human Alarm Response Capabilities .................................................................................. 47

Operators and Alarms in Analog and Digital Control Rooms ….............................................48

In situ NPP Operator Development...................................................................................

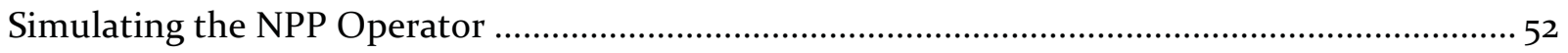

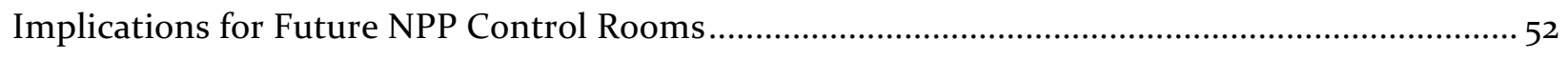

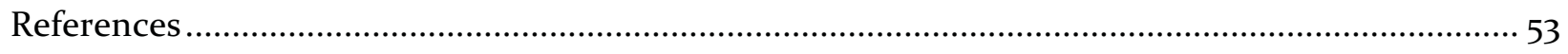




\section{Executive Summary}

By definition, alarms serve to notify human operators of out-of-parameter conditions that could threaten equipment, the environment, product quality and, of course, human life. Given the complexities of industrial systems, human machine interfaces, and the human operator, theunderstanding of how alarms and humans can best work together to prevent disaster is continually developing. This review examines advances in alarm research and development from 2000 to 2010 and includes the writings of trade professionals, engineering and human factors researchers, and standards organizations with the goal of documenting advances in alarms system design, research, and implementation.

A semi-structured search paradigm was used to identify literature to review. Relevant material was identified from the initial search returns and a less structured examination of works cited was used to identify other potentially relevant sources of information. Over 100 sources were considered for the review and were divided into six broad categories: 1 ) trade / professional publications, 2) alarm processing \& analysis, 3) alarm guidelines, 4) alarm prevention, 5) alarm presentation, and 6) human response to alarms.

Review of the trade / professional publications reveals an increasing awareness of alarm related problems. A number of trade articles attest to what is called by some to be an "alarm explosion" promoted by the use of distributed control systems. In response, many trade articles highlight the need for a well defined alarm philosophy and rationalization and the application of nascent alarm management guidelines. Others describe improvements in alarm management in the process industry when rationalization and guidelines have been implemented.

Alarm analysis and processing research and development typically aims to reduce the number of alarms presented to an opertator. Recognizing that the objective of an alarm will likely be lost in the flood of alarms that face contemporary control room operators, a number of alarm management methods have been developed to reduce the total number of alarms and increase the information conveyed by those alarms that remain. Development in this area during the review period represents a mix of engineering solutions, of which only a few are accompanied with operator performance data. Simple alarm reduction appears to be the overarching bias in the alarm analysis and processing, where less is considered to be more.

The numerous guidelines with regard to alarms and alarm management reflect differences in the maturation of alarm system philosophies across industries. The process industry appears to rely heavily on guidelines from the Engineering Equipment and Materials User Association (EEMUA 191) and the ANSI/ISO 18.2 whereas the nuclear industry has relied on NUREG-070o. Close examination of the guidelines reveals that none could be considered exhaustive. The process industry guidelines tend to focus more on the management and procurement of alarm systems while the nuclear industry tends to focus on the human machine interface components. These guidelines are written to different audiences and designers should consider using combinations of all of the relevant guidelines to best address their unique alarm circumstances. 
Operators are actively involved in alarm prevention. The success with which this can be accomplished depends on an operator's ability to conceptualize a complex process, understand the relationships among many variables and predict future system states. The literature describes several alarm prevention methods designed to provide operators with the information needed to better perceive, comprehend, and predict system states with the goal of preventing alarm conditions.

The alarm presentation literature is diverse. A number of authors have performed heuristic evaluations of existing alarm systems while others have considered the design of new alarm system components including tiles, displays, and auditory components. Although advances have been made in the design of alarm system components, the quantity of advancements appears somewhat disproportionate to the technological possibilities. Moreover, little research has been performed to evaluate how the new components affect operator performance.

The human response to alarms literature represents the largest aspect of this review. This literature considers a number of topics including the application of signal detection theory, effects of alarm reliability, modeling of the human response to alarms, and effects of display configurations on performance. Findings from a number of studies substantiate a growing knowledge base concerning the effects of false alarms and operator workload. That being said, the last 10 years of research in human response to alarm has been relatively confined leaving many issues unaddressed. 


\section{Introduction}

The aging of the US Nuclear power plants (NPP) has created a unique advancement opportunity in the area of alarm management. While manufacturers of NPP worldwide have continued to develop and advance power generation, many if not all of the United States' light water nuclear power plants stand at a crossroad. With extended life ahead of them and the inevitable obsolescence of existing systems, asset owners and plant operators are looking to modernize their instrument and control systems. Attendees of the Light Water Reactor Sustainability Workshop held in August 2009 (Hallbert, Persensky, Smidts, Aldemir, and Naser, 2009) described a variety of challenges faced by NPP plant operators whose power generating capabilities have essentially out-lived their instrumentation and control capabilities. One challenge is how best to capitalize on what has been learned about the use of alarms and alarm management methods. The report from the workshop notes that, "Alarm management is an area of continuing concern in complex system design." To the extent that NPP can learn from the years of experience other industries have gained working with a continuingly maturing alarm technology, the more likely it is to avoid its mistakes and bootstrap off its successes.

To facilitate the transfer of knowledge, this document reviews the last 10 years of research and development in the area of alarms and alarm management. The report reviews alarm related literature with the goal of identifying key findings and directions that might affect the design and implementation of the next generation alarm system. Literature in the following arenas has been considered in the review process:

- Professional and trade journals

- Peer reviewed research publications

- Conference proceedings

- Marketing materials

- Alarm guidelines

\section{Alarms Project Literature Search Process}

A systematic search process was used to identify potentially relevant literature. With the assistance of a librarian at the Idaho National Laboratory, combinations of the following terms were used to query 44 databases between the years 2000 - 2010:

- $\operatorname{alarm}(\mathrm{s})$

- alarm management

- alarm system

- alarm approach

- alarm philosophy

- alarm processing

The search returned 925 titles minus duplicates. These titles were reviewed and 131 abstracts were identified and secured for a more in depth analysis. Review of the abstracts determined that 47 
articles should be included. These articles were obtained from the INL and University of Idaho libraries. Simultaneously, another literature search was performed, using another library system, of EBSCOhost, IEEE Xplore, and ACM Digital Library. Also, the reference sections of NUREGs, reports, standards, and guidelines were reviewed to identify any other pertinent literature that might have been missed during the previous steps. All resulting documents were reviewed to determine if inclusion in this review was appropriate.

\section{Overview of Identified Literature}

As might be expected, the wide net cast to identify alarm related literature returned a broad assortment of documents and publications. From a macro perspective, the identified body of literature fit within six different categories as shown in the Venn diagram in Figure 1 below.

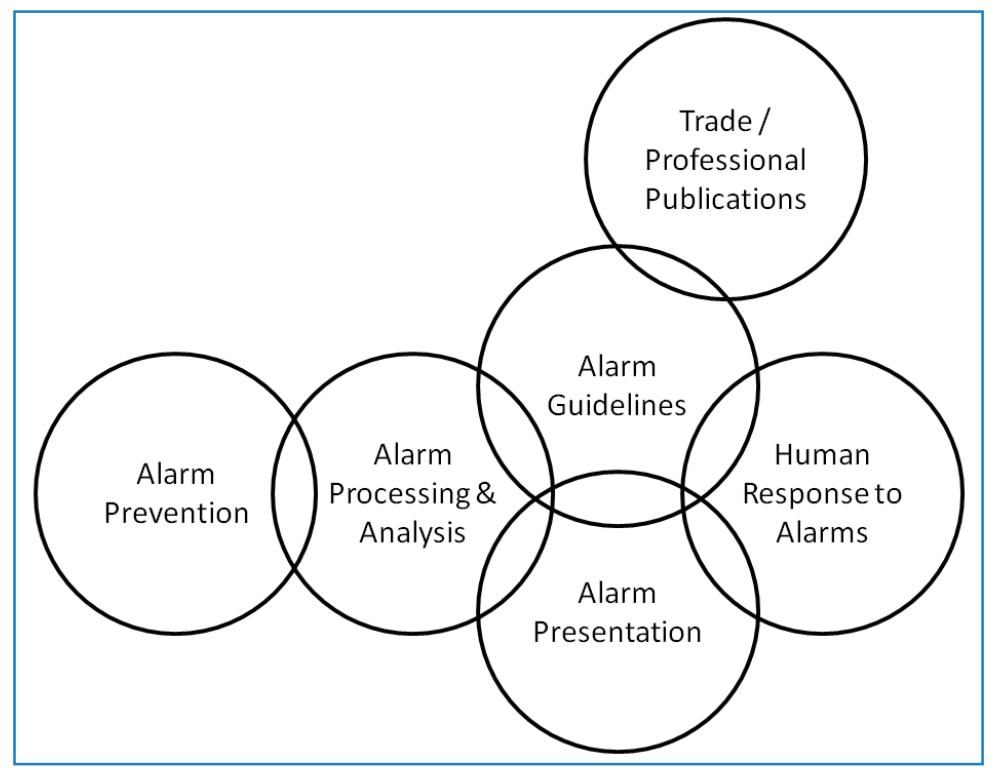

Figure 1 Conceptual organization of alarm literature published from 2000 to 2010

The Trade / Professional Publications encompass the variety of trade magazines and journals within the process industry. Articles from these sources were included to provide a perspective from the applied community. A number of these articles speak to the problems many digital process control rooms face. Alarm floods, alarm expansion, alarm redundancy, nuisance alarms, and many other alarm related obstacles are discussed. At a minimum, these documents point to the very real conditions in process control rooms that rely on distributed control systems (DCS). More importantly, the problems described in the trade and professional literature often serve to identify issues and circumstances the NPP could and should avoid as it modernizes its control capabilities. 
A variety of the identified sources are guidance documents that provide instruction and direction for the design and procurement of new alarm systems or the refinement of existing alarm systems. These guidelines come from equipment manufacturer advisory groups working in the process industry, standard groups within the telecommunications industry, groups formed by foreign governments, and the US Nuclear Regulatory Commission. A brief comparison of existing guidelines from varying industries reveals differences in developmental progress.

The Alarm Processing \& Analysis literature consists of a number of methods used to reduce the number of alarms presented to an operator. Only one of the reviewed methods appears to have been commercialized. Literature in this area tends to describe engineering solutions to alarm management, including process modeling methods and statistical methods that can be used to reduce the number of alarms an operator might experience. While these methods have demonstrated success, the administrative intervention of alarm rationalization appears to be as, or even, more successful in reducing the number of alarms operators must manage.

Alarm Prevention might be categorized as a unique facet of Alarm Processing \& Analysis; however, as the category name implies, the goal is to prevent alarms from occurring by providing operators with the tools and information needed to anticipate a state that exceeds alarm thresholds. Arguably, other Alarm Processing \& Analysis methods accomplish the same outcome, yet a number of the reviewed analysis methods start with alarm data as the input. Alarm prevention starts with the characteristics of the processes being managed. While this distinction might be subtle, discussions of alarm prevention and alarm processing lead to distinctly different methods.

Literature within the Alarm Presentation section tends to be more closely related to more traditional Human Machine Interface work. This section consists of articles that describe the design and layout of annunciator panels, the configuration of alarm tiles on configurable displays (e.g., LCD displays), auditory alarms, and the use of automatically resetting alarms.

The Human Response to Alarms literature examines how the human operator responds to the alarm system and how that response is influenced by the number of alarms, the presence of nonalarm information, and alarm reliability and false alarms. The research relies heavily on Signal Detection Theory as a method of modeling the complexities of alarm response. Observations of NPP operators suggest that these individuals are engaged in more than a simple vigilance task. In fact, rather than being simple monitors, operators become an integral part of the plant operational system.

\section{Review Caveats}

The goal of this review is to describe research and development in the alarms arena over the last 10 years. Although the review focuses on alarms, no one section can be considered to be exhaustive with regard to the subtopic addressed. Each section itself could be the genesis of a separate literature review. Reasonable efforts were taken to identify salient literature in domain as a whole, but we acknowledge that this arbitrary slice of R\&D time (2000 - 2010) will

8 Introduction | Benchmark Research \& Safety, Inc. 
undoubtedly fail to treat any of the sub domains with the breadth of scope or depth of analysis commensurate with more traditional literature reviews.

\section{Trade/Professional Publications}

In no other place within the body of alarm related literature is the case for effective design of alarms and the implementation of alarm management made more obvious than in the collection of industry and professional publications. Several authors point to the exponential increase in the number of alarms in the variety of industries. Traub and Hudson (2007) describe how large number of alarms contributed to incidents within the rail and marine transportation industries. Wallin (2009) describes the impact of ridiculous alarm rates in the telecommunication industry. Bransby (2000) noted that the escalators used in the Jubilee Extension part of the London subway system had 100 different alarms. Examples of inadequately designed alarms, and the problems they can create, can be found in many industries.

Grosdidier, Connor, Hollifield, and Kulkarni (2003) measured the alarm frequency for an operator workstation in a European refinery. Over an 18 day period, the operator experienced an average of 14,250 alarms per day. The authors also reported instances where the number of alarms per day was in the "six-figure category" (p. 59). Figure 2 below shows the number of alarms experienced at the operator workstation over the period data were collected. The authors noted that the alarm system suppressed 83 percent of alarms created by the Distributed Control System (DCS) leaving the operator to manage an average of 2,422 alarms per day. For an 8 hour shift, that is equal to approximately 5 alarms per minute.

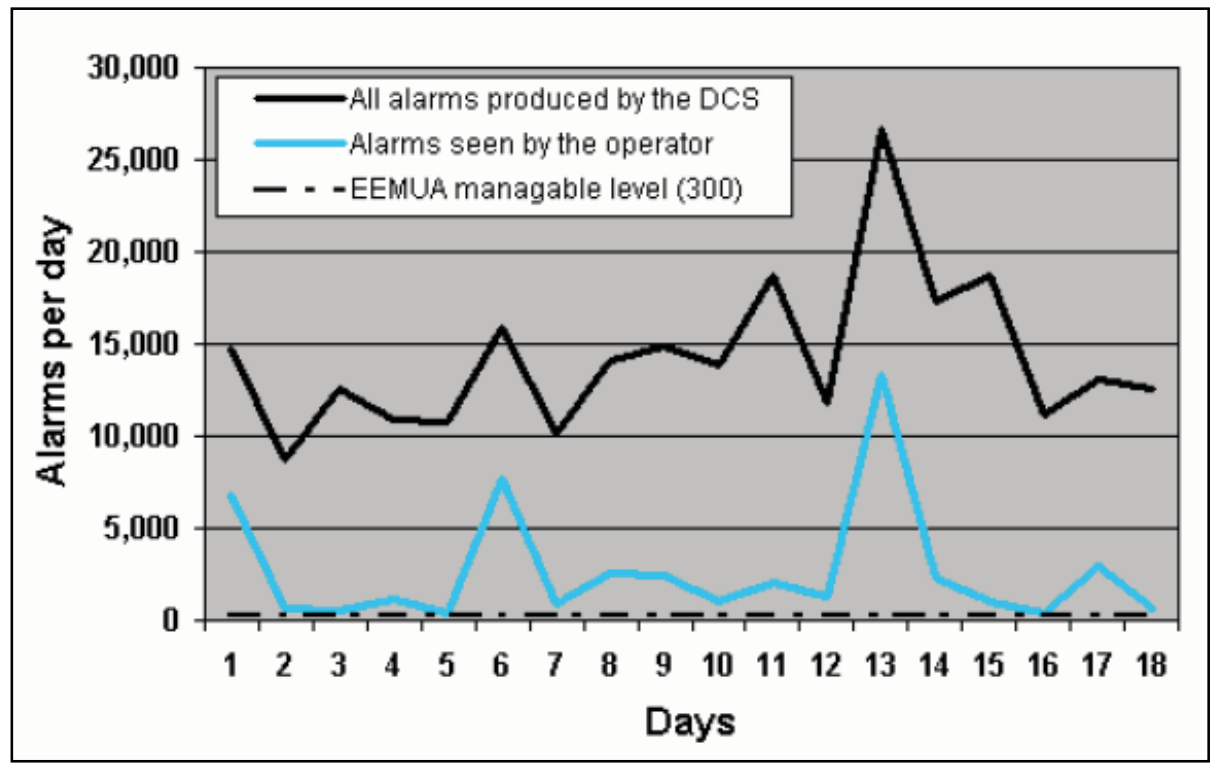

Figure 2 Number of daily alarms experienced by an operator in a European refinery (Grosdidier, Conner, Hollifield, \& Kulkarni, 2003, p. 59). 
The DCS is the most commonly identified contributor to the seemingly endless increase in the number of alarms. Grosdidier, Conner, Hollifield, and Kulkarni (2003), Goble and Stauffer (2007) and others make the case DCS technology has allowed the number of alarms to grow well beyond the number of measured process variables. Grosdidier's et al. (2003) review of 42 operator workstations revealed that there was an average of 2.6 alarms for every alarmable variable. The authors noted some instances where there were four or more alarms associated with a single alarmable variable. Figure 3 depicts the number of alarms associated with a measured process variable depicted on the workstations they reviewed.

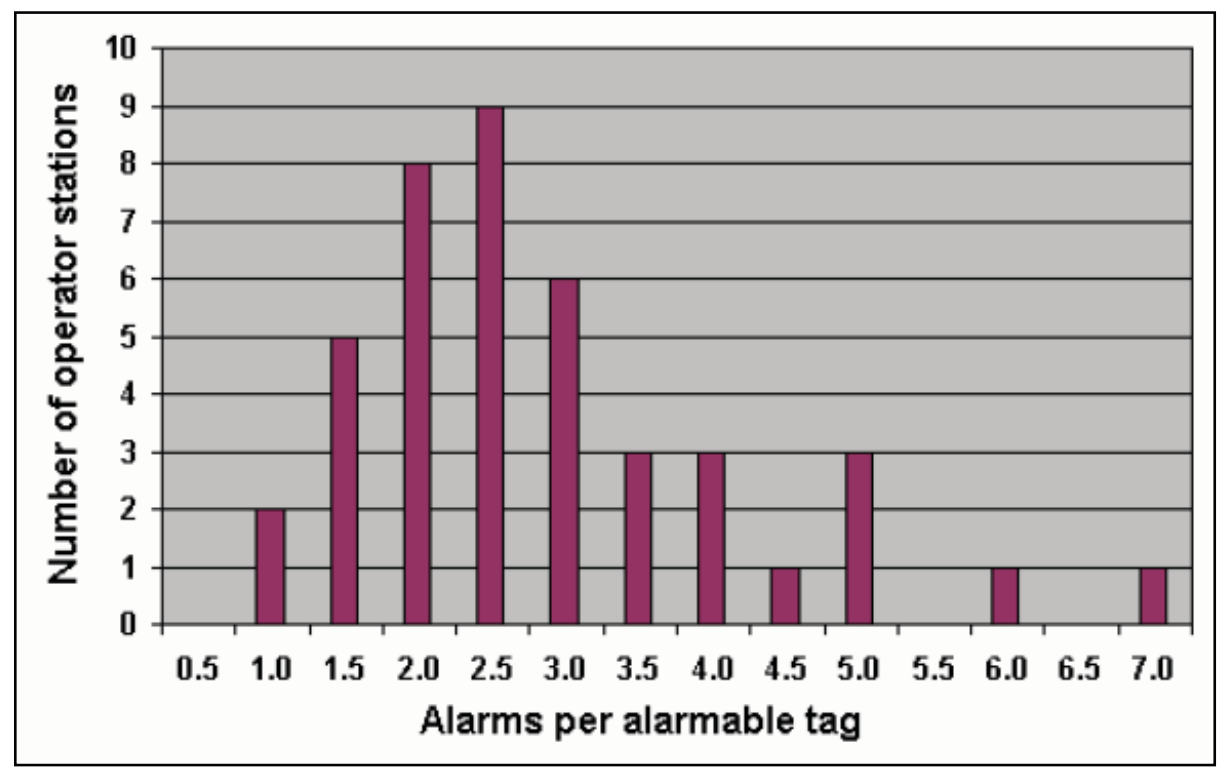

Figure 3 Number of alarms per measured variable found on 42 operator workstations (Grosdidier, Hollifield, \& Kulkarni, 2003, p. 60).

While the DCS enables the production of alarms, the device itself only follows its programming. Ultimately, the activities of the DCS reflect the extent to which plant designers and operators understand the often abstract nature of the processes they control. In the absence of a clear understanding of how an organization will use alarms, and what should be alarmed (i.e., an alarm philosophy), plant engineers are often motivated to add more alarms to ensure that potentially critical elements are not overlooked. This unguided approach to alarm design has been eluded to by a number of authors and suggests that larger portions of organizations, particularly upper management, should be involved in the design of alarm systems.

Citing data from the Abnormal Situation Management Consortium, O'Brien (2008) notes that a deviation alarm within a regulated industry costs between $\$ 2,000$ and $\$ 6$, ooo per alarm with unplanned incidents costing between $\$ 100,000$ to $\$ 1$ million. Data gathered by Grosdidier, Connor, Hollifield, and Kulkarni (2003) suggests that alarm floods can increase the likelihood of these deviations even when a deviation does not exist. Given the underlying expense of poorly implemented, unmanaged, or actual alarm events, O’Brien contends that “... alarm management should be looked at not as a technology, but as a business enabler and risk management 
investment" (p. 124). O’Brien's comment draws other components of the organization into the alarm system discussion. Pai (2008) comments that operators, control engineers, and plant managers all see the benefits of alarm management differently correspond with O'Brien's assessment that alarm systems should be viewed as business as well as risk management tools. Accordingly, advocates of efficient and effective design of alarm systems, or the application of alarm management strategies, will be buoyed in their efforts when their message effectively addresses varying layers of an organization. This type of broad messaging appears to be critical for the design and implementation of alarm management, as well as the long-term maintenance of these efforts.

\section{Alarm Management Success Stories}

The professional and trade journals that include discussions of alarm systems have highlighted a number of alarm management success stories from 2000 to 2010. These success stories suggest that plant managers can make substantial improvements in their alarm technology by using alarm rationalization methods of measuring, analyzing, and refining existing alarms. In many instances, this rationalization and refinement process is supported by technology that monitors and analyzes the occurrence of alarms. For example, an alarm management software application implemented at a concrete processing plant by Adroit Technologies in conjunction with an alarm rationalization process significantly reduced the number of alarms presented to plant operators. Prior to the rationalization process, the plant experienced 540 incidents per hour. After 24 hours of alarm monitoring and modifications to the "bad actors," the plant experienced a $35 \%$ improvement in a single benchmark (Advanced Alarm Management, 2009). Similarly, Diamond and Dhalla (2004) used a Matrikon product to analyze the alarms occurring in the control room of Air Products. By analyzing alarm data and addressing what were termed "bad-actors" by modifying their configurations, Air Products was able to reduce the number of alarms by more than 80 percent in two months.

From a macro-level, implementing an alarm tracking and management technology is the result of developing and implementing an alarm philosophy for an organization and taking the steps to rationalize each alarm. Mostia (2005) advocates for alarm rationalization as a means of managing the ever increasing amount of alarm information facing contemporary plant operators and provides an eight-step process designed to manage what he calls an "out-of-control" alarm system. Efforts by process plants to rationalize alarms have proven to be successful.

At least three other authors attest to the value of developing an alarm philosophy and an alarm life cycle process. Szudajski and Hull (2007) describe the process and results of implementing an alarm philosophy and rationalization process at the Salt River Project, a power producer in Arizona. Prior to implementing the philosophy, the operators were inundated with alarms. "In one 18-hour period, operators confronted 5,00o alarms, every one of which required intervention of some sort. And 98 percent were designated top priority (p. 34).” After the alarm rationalization, 11 percent of alarms were categorized as priority one, 14 percent as priority two, and 75 percent as priority three. Considerable gains can be made with the application of 
administration interventions, specifically a process to rationalize each alarm. This plant and its alarm management efforts are also described by Gaertner (2007).

Monsanto's phosphate processing facility experienced significant reductions in alarms after applying the Six Sigma process to their alarm system (Six Sigma, February 2008; March 2008). Plant staff evaluated the plant alarm process using the Six Sigma process of analyzing, improving, and controlling processes. This work, performed at an elemental phosphorous plant in Idaho, USA, yielded a $62 \%$ reduction in operator loading when alarms from the plant's three furnaces were subject to a rationalization process. Finally, Wilmarth (2010) describes the changes in alarms experienced in a plant producing ethylene, polyethylene, and hexane. Prior to the development and implementation of an alarm rationalization process and an alarm philosophy, plant operators experienced over 120 alarms per hour. The plant engaged in efforts to measure, analyze, and rationalize the existing alarms and worked with a consultant to develop an alarm philosophy. After 29 months of efforts aimed at managing the plant's alarms, the hourly alarm rate was approximately six per hour.

Using articles in trade/professional journals regarding alarm rates may over estimate the alarm problem. While there instances where alarm rates appear ridiculously high, it is unlikely that data concerning well designed and managed alarm systems would be published. Working with the Abnormal Situation Management Consortium (ASM), Reising and Montgomery (2005) publish alarm data from 40 different consoles. ASM members submitted alarm data to the authors who then analyzed it in an effort to determine if the alarm rates guidelines outlined in the Engineering Equipment and Materials User Association's (EEMUA) guide on alarm management were attainable. Figure 4 below depicts the alarm rates for the consoles analyzed. The majority of consoles had alarm rates below or close to the defined rate. In an upset condition, however, only two of the evaluated consoles come close to the guideline. In contrast to methods aimed at the alarm system overall, systems and methods that can aid operators during these upset conditions are relatively rare. Methods that have been commercialized, evaluated or proposed are discussed in the section on alarm processing and analysis.

\section{Advocating Alarm Guidelines}

A portion of the professional and trade journals addressing the alarm systems has been dedicated to advancing the implementation of the alarm guidelines such as EEMUA 191 and ISA 18.2. Martinez (2008), for example, encourages process control engineers to treat alarm planning like equipment planning. Alarm systems should be engineered, maintained, and reviewed. He points to EEMUA 191 and ISA 18.2 as a starting point for the design or redesign of an alarm system. Similarly, Dunn \& Sands (2005a, 2005b) ISA-SP18 - Alarm Systems Management and Design Guide) provide an overview of ISA 18.2 Alarm Systems Management and Design Guide and encourage its use as a foundation for an efficient and effective alarm system. Other authors, including O'Brien (2008), Hollender and Beuthel (2007) and Goble and Stauffer (2007), also promote the use of alarm system guidelines. 


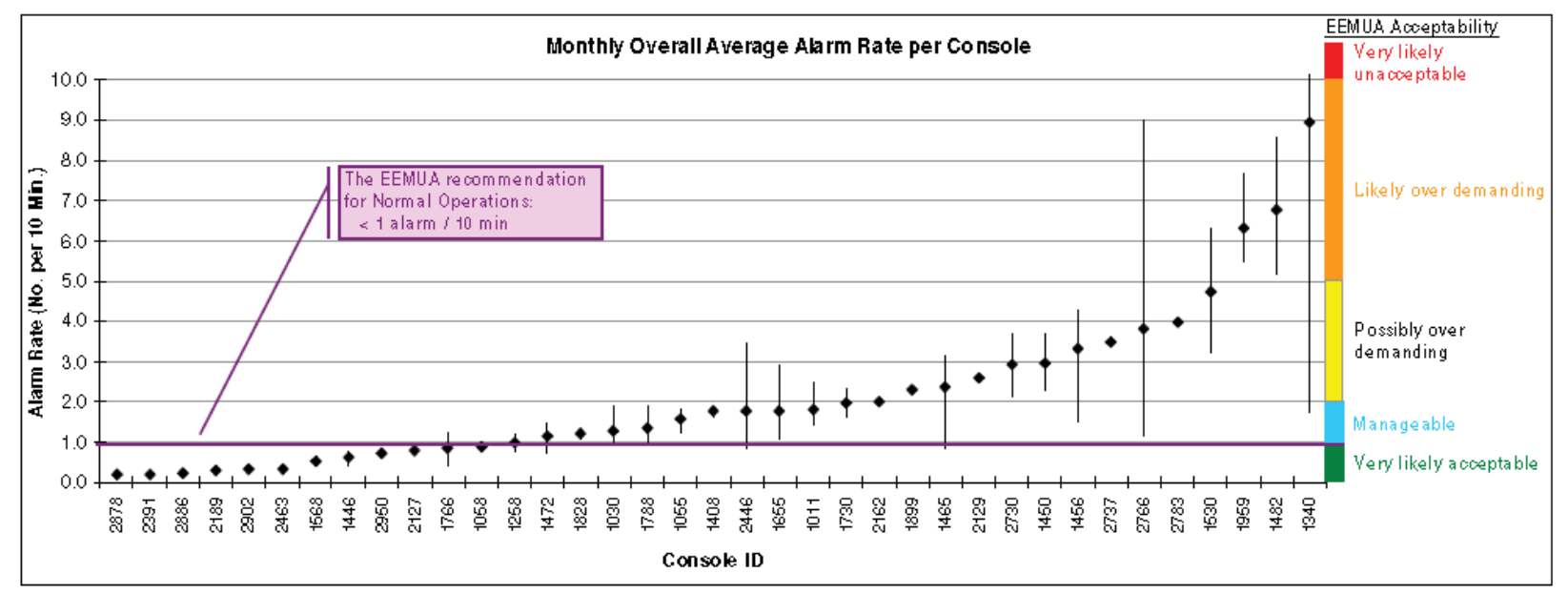

Figure 4 Alarm rates from three months of data submitted from 40 consoles. Data represent the average alarm rates per 10 minute interval. Bars depict the maximum and minimum values for alarms in the same interval (Reising \& Montgomery, 2005, p. 4).

Tanner, Gould, Turner, and Atkinson (2005) are somewhat unique in advocating the implementation of available alarm guidelines. Their article applies the guidance from these documents to the realities of implementing an overarching alarm philosophy, rationalization, and maintenance program in an existing process facility. The authors walk through the various steps that are taken to measure, analyze, and improve alarm systems and the management of change processes needed to ensure that improvements remain in place amidst the changing configuration of the process and the plant. Hatch and Stauffer, both members of the ISA 18 committee, take the ANSI / ISA guidelines and relate them to the requirements of ANSI 61511/ISA 84, Functional safety: Safety Instrumented Systems for the Process Industry Sector, and a Layer of Protection Analysis (LOPA) and show how these standards, methods, and guidelines can be used together in the design of an alarm philosophy. Additionally, the authors outline a number of alarm HMI guidelines for how an alarm system should be implemented (Hatch \& Stauffer, 2009).

Many of the trade journal articles don't differentiate safety alarms from product quality alarms. When there is a cacophony of alarms, the difference might be moot. Alford, Kindervater, and Stankovich (2005) note that alarm systems extend beyond what might traditionally be thought of as operating safety limits of the plant to include systems that monitor product quality or plant emissions. The authors note that the substances used during a chemical process may subject a plant to requirements promulgated by the Occupational Safety and Health Administration (OSHA; cf. 29 CFR 1910.119 Process Safety Management) or the Environmental Protection Agency (EPA; cf. 112(r) 40 CFR 68 Risk Management Plan - Prevention Program). If the plant's output falls within the purview of the US Food and Drug Administration, alarm systems might be subject to that agency's Guide to Inspection of Computerized Systems in Drug Processing. Regardless of what is being produced, it is likely that safety is only one of several objectives a process plant must meet. Other objectives include protection of the environment, assets, production rates, and 
product quality. It is likely that alarms could be generated for any of these objectives. If not adequately prioritized, these additional alarms can quickly mask safety critical alarms.

\section{Alarm Management Missteps}

Marvin and Eng (2005) who work for Matrikon, an alarm management vendor, identified 12 obstacles to the effective implementation of an alarm management program. These include:

- Inadequate project management

- Use of wrong or inadequate analysis tools

- Failure to adequately benchmark the existing alarm system without which alarm management changes cannot be justified

- Absence of clear alarm rationalization guidelines

- Failing to include control room operators in the alarm management design process

- Selecting analytical tools based on cost, not features

- Inadequate use of automation

- Focusing exclusively on alarm occurrences without considering the actions of the operator

- Treating alarm data equally when differences in priority exist

- Failing to provide operators with training on alarm management methods

- Failing to adequately employ management of change methods to prevent steep learning curves during alarm system transitions

- Failing to assign roles and responsibilities

As NPPs consider the migration from analog to digital control systems, avoiding these obstacles should increase the ease and success with which new technology is introduced into the control room.

\section{Alarm Processing \& Analysis}

Alarm processing and analysis describes the broad range of methods, actions, and processes used to analyze, transform, prioritize, correlate or mine alarm signals or alarm histories in order to present operators with more meaningful alarm signals while reducing alarm overloads, cascades, repetition, perseveration, or other undesirable alarm condition. NUREG-o7oo identifies a number of alarm processing methods that have been widely discussed in industry trade publications. These include:

- First-out processing: The identification of the initiating event associated with a plant trip.

- Mode dependence processing: The display or suppression of a warning dependent on the mode or state of the plant.

- System configuration processing: The display or suppression of a warning dependent on the configuration of the system.

- Logical consequence processing: The suppression of alarms consequent to an initial event. 
- Exceptions to expected alarm patterns: The display of alarms that are not expected given the alarm processing in use.

- Alarm prioritization: Alarms should be accompanied by information that conveys its level of urgency (NUREG-070o).

- Alarm filtering: The elimination of alarms that have no current operational significance.

In light of the over abundance of alarms in many contemporary control rooms, reductions in alarms may indeed be welcomed. Few would argue with the idiom that "less is more," in many of these situations. The adoption of these alarm processing methods appears to have occurred without any recent reference to operator performance. In the 10 year review of research in the alarm domain, only one study appears to have examined the impact of these techniques an operator's ability to efficiently and effectively operate the plant or process. The absence of substantive human performance research, with regard to alarm processing methods, should not diminish the value of reducing the number of alarms so as to increase the signal-to-noise ratio; however, the complexity and criticality of the plants and processes that use these systems warrant a clearer understanding of how these processes might affect an operator's ability to perceive, understand, and predict current and future states.

\section{Empirical Research on Alarm Processing Methods}

O’Hara, Brown, Hallbert, Skråning, Persensky, and Wachtel (200o) published the only identified study that examined the effect of alarm processing methods on operator performance. O'Hara and his colleagues used a full-scope nuclear power plant simulator control room in Halden, Norway, to evaluate the effect of two types of alarm processing on the operation of the simulated plant and on the operators themselves. Six, two-person crews completed low and high complexity scenarios that involved alarms and annunciators where one of three levels of alarm processing was present: no alarm processing, nuisance alarm reduction, and nuisance and redundant alarm reduction were compared. Nuisance alarms were defined as:

- Indicating the status of a component

- Alarm triggered by momentary system fluctuations

- Alarms irrelevant to the current operational mode

Redundant alarms were defined as valid alarms that replicated information the operator already possessed. Eliminating nuisance alarms reduced the total number of unprocessed alarms by 50 percent. Reductions of nuisance and redundant alarms eliminated upwards of 75 percent of the unprocessed alarms.

Analysis of the operator performance data obtained by O'Hara et al. (200o) showed that operator performance in the nuisance and redundant condition was superior to that of just the reduction in nuisance alarms alone. Operators reported a clear preference for high levels of processing (see Table 1 below). Operators noted that the reduction of nuisance and redundant alarms eliminated unnecessary information promoting the detection of what was important. 
Table 1 Summary of operator preference rankings of alarm processing levels O’Hara, Brown, Hallbert, Skråning, Persensky, and Wachtel (200o)

\begin{tabular}{|l|c|c|c|}
\hline & \multicolumn{3}{|c|}{ Preference Ranking } \\
\hline $\begin{array}{c}\text { Level of Alarm } \\
\text { Processing }\end{array}$ & Most & Moderate & Least \\
\hline No processing & 0 & 0 & 12 \\
\hline $\begin{array}{l}\text { Reduction of nuisance } \\
\text { alarms }\end{array}$ & 2 & 10 & 0 \\
\hline $\begin{array}{l}\text { Reduction of nuisance } \\
\text { and redundant alarms }\end{array}$ & 10 & 2 & 0 \\
\hline
\end{tabular}

Other comments by operators might have some bearing on the design of alarm processing systems including:

- The complexity of the alarm processing system should not exceed the operator's ability to comprehend what the system is doing

- Higher levels of processing might remove important information

- Alarm processing should be implemented cautiously

- The ability of an operator to select the level of processing might cause confusion among other operators

- Acceptance of a reduced alarm set is related to the confidence in the system used to process the alarms

All of these concerns should be considered when implementing an alarm processing system.

\section{Additional Alarm Processing Methods}

A number of different post-hoc alarm processing methods have been described in the alarm literature. Most of the methods appear to be in the development stage. One method that uses a graphical representation has been commercialized by GoalArt, a Swedish company.

\section{Graphical}

Jan Eric Larsson at GoalArt, and his colleagues at IFE Halden and Orsted-DTU Technical University of Denmark (Larsson et al., 2005, 2006a, 2006b; Tuszynski et al., 2002), have developed an alarm management system using Multilevel Flow Models (MFM), a graphical method used to characterize the connections and interdependencies of components with a system. The circulation system represented in Figure ${ }_{5} \mathrm{~A}$, for example, is represented graphically using MFM in Figure ${ }_{5} \mathrm{~B}$. 


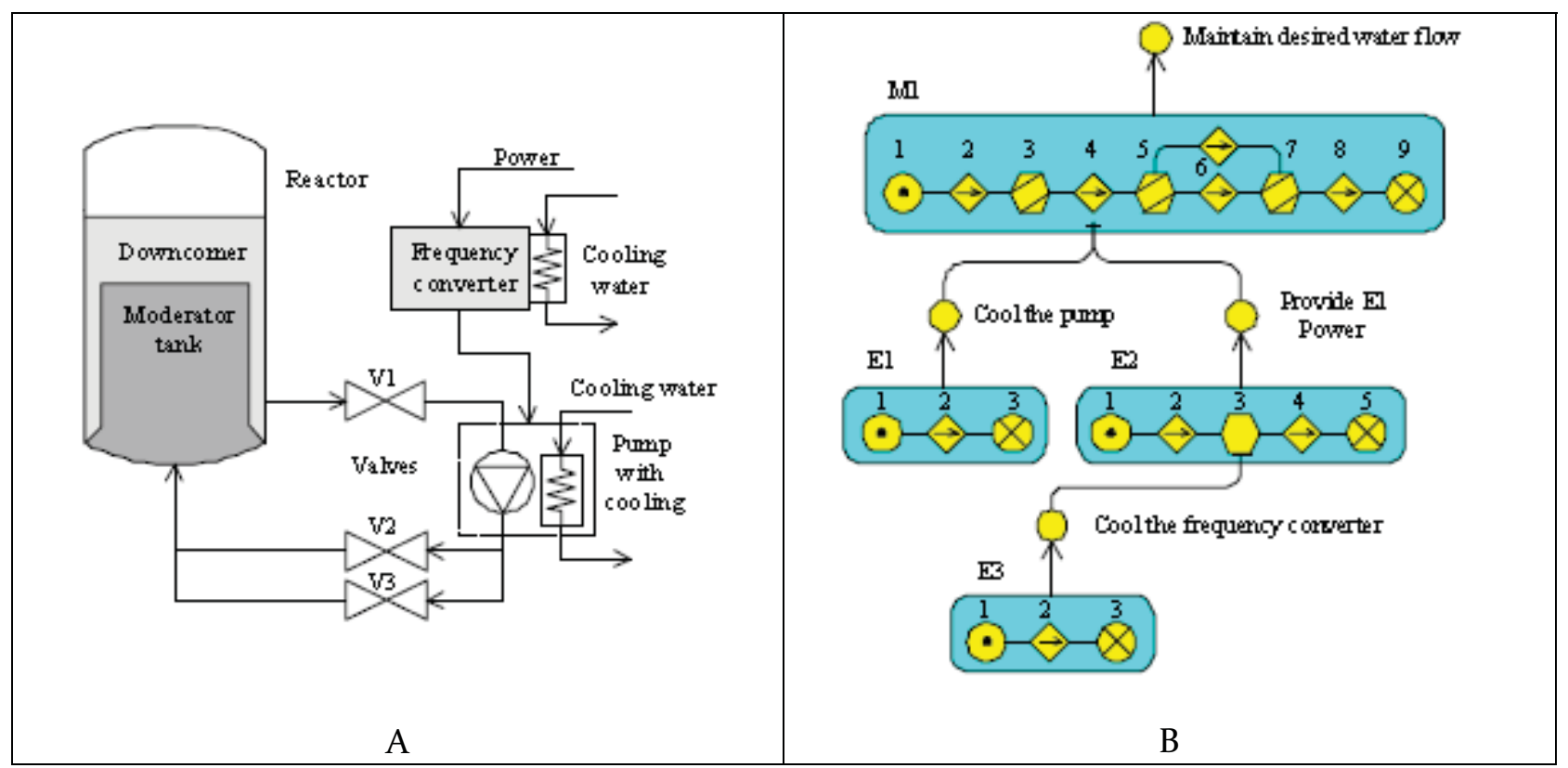

Figure 5 Representation of recirculation system as functional schematic (A) and multilevel flow model (B) (Larsson, Öhman, Calzada, Nihlwing, Jokstad, Kristianssen, Kvalem \& Lind, 20o6, np).

Larsson has developed a number of algorithms that use the MFM diagrams to detect and present a variety of different information to operators. These algorithms include:

- Sensor validation for the detection of faulty sensors and leaks in quantitative and discrete sensors

- Alarm analysis that differentiates primary and consequential alarms

- Fault diagnosis that identifies the root causes of faults

- Action planning that provides operators with recommendations for corrective actions

- Failure mode analysis that projects future consequences of actions or failures

The MFM-based algorithms are effective in reducing the number of alarms presented to operators. Information from GoalArt shows dramatic reductions in the number of alarms generated. In the case of an electrical blackout in Sweden, GoalArt promotional material reported a $99.6 \%$ reduction in the number of alarms (Larsson, 2010).

Srinivasan, Liu, Lim, Tan \& Ho (2004) created an intelligent alarm management system using univariate statistical procedures to suppress nuisance alarms. This system uses a combination of algorithms, process knowledge, and control system expertise to address two types of nuisance alarms: 1) repeating alarms and 2) standing alarms that persist due to the dead-band when the triggering condition is no longer valid which causes an increase in the time to clear an alarm. The authors developed an algorithm that computes the moving average of an alarmed variable. Using the average value of the variable and a measure of variability (i.e., standard deviation, $\sigma$ ) the alarm management system dynamically changes the alarm threshold. When a reoccurring alarm is detected, the alarm threshold is lowered to a point equal to the average variable reading $\pm 2 \sigma$. This will cause the alarm to be in alarm status. When the measured state falls within $2 \sigma$ of the 
average, the original alarm threshold is returned. If the alarmed variable exceeds $\pm 3 \sigma$ of the average, the reduced threshold would remain. Using this method, the authors were able to reduce the number of nuisance alarms from 390 to 90 during the day data were gathered. The alarm management system also allows operators to tag specific alarms which are then filtered by the system. Operators will often tag these alarms during plant upsets. The alarm management system reinstates these alarms when the measured variable falls within $\pm 3 \sigma$ of the average. The authors report that this system has reduced the number of alarms by $50 \%$.

\section{Proposed Alarm Processing Methods}

Numerous authors have proposed other alarm processing methods, a large portion of which are simply concepts that might be used, or are processes that have yet to be fully developed. Foong, Sulaiman, Rambli, and Abdullah (2009) used fuzzy-logic to prioritize multi-alarm events in a crude oil distillation unit in Malaysia (see also Parasuraman \& Masalonis, 200o). This system analyzed sensor data and configuration specifications from a knowledge base to determine the priority of an alarm. Geng, Zhu and Gu (2005) proposed the use of similar fuzzy-logic algorithms to group and cluster alarm events. Geng and his colleagues validated their system using alarm data from an ethylene cracking furnace alarm system. Jang, Seong, Keum, Park \& Kim (20o8) proposed a system-integrated modular advanced reactor-alarm system, SMART-AS, that accessed and processed information contained within a database. This system was designed for a nuclear power plant and in addition to reducing the number of alarms is capable of recognizing specific plant conditions. Larraz (2007) details the use of Markov chains as a method of characterizing and manipulating alarm data. By examining alarm probability matrices, an analyst can identify high probability alarms and identify the conditional probabilities associated with consequential alarms. Aizpurúa, Galán, and Jiménez (2008) propose the use of an ontological representation of the system that, like MFM, creates hierarchical relationships among systems that allow for the filtering or suppression of consequential alarms. Jang, Keum, Park, and Kim (2008) propose using data mining of the alarm event database to extract rules that can be used to reduce the number of alarm presented to operators. Similarly, Lambert-Torres, Fonseca, Coutinho, and Rossi (2006) mined the alarm history of the San Paulo Transmission System Company to classify alarm information and delete unneeded information. Their analysis and subsequent algorithms significantly reduced the number of alarms that would otherwise reach the operators. Kettschau, Brück and Schefczik (2002) described a correlated alarm simulator that was designed to find generic patterns in the alarm event data using a moving time window. When patterns of alarms matched an existing pattern, the identified root cause of that alarm event was identified. A correlation-based alarm reduction method that filters specific alarm patterns was also described by Jukić, Halusek and Špoljarć (2009) and Zupan and Medhi (2003).

\section{Alarm Prevention}

In the last 10 years, the vast majority of research and development has focused on managing alarms once they have been generated. What if the alarm could be prevented in the first place? Because all faults are not equal, operators with sufficient insight into the operation of a process 
can prevent alarms before they happen. The challenge is to identify those conditions that are highly predictive of alarm states. One study has evaluated the utility of a pre-alarm system that detects and notifies operators of conditions predictive of alarms. Other studies and systems have endeavored to characterize systems in ways that allow operators to further prevent alarms.

Hwang et al. (2008) devised a pre-alarm system for a PC-based nuclear power plant simulator using five quality control rules. Operators were alerted to conditions that met one or more of these five rules:

1. Any one point falls outside the upper control limits or lower control limits

2. Seven points in a row are continually changing in the same direction

3. Cyclical patterns or points occur

4. Two out of three consecutive points fall beyond the two-sigma limit

5. A run of five points falls beyond the one-sigma limit

The pre-alarm conditions were presented in a graphic and text display. The simulator's default alarm system was also used. Twenty-six participants completed two simulated operations in normal and abnormal conditions and the researchers gathered performance, mental workload, and situation awareness data. When a pre-alarm condition occurred, the research participants were required to respond by pressing a key on the keyboard that would prevent the occurrence of the related alarm. If the participant did not respond to the pre-alarm, the simulator's alarm would sound.

The data revealed a significant reduction in mental workload as measured by secondary task performance. Secondary task performance for the pre-alarm condition was greater than that of the traditional alarm condition, indicating the presence of greater spare mental capacity. The results of the NASA TLX workload data revealed a similar pattern. Data concerning the frequency of alarms showed a significant reduction in the number of alarms when comparing the pre-alarm and conventional alarm methods. Varying alarm formats had no discernable effects on situation awareness.

Hwang and his colleagues conclude that a pre-alarm system is needed as a means of preventing alarms. Their data support this conclusion; however, their methods and findings appear to point to the larger issue of awareness. The results suggest that operators can operate a complex system within established parameters when they are supported by higher-level tools that can integrate and analyze data across time and across components. The availability of what might be called situation assessment support tools that detect conditions predictive of alarms does not negate the need for alarms. Faults and failures will still occur and will require alarms. The presence of situation assessment support tools can shift the emphasis from alarm management to system operation with the goal of promoting efficiency and alarm prevention.

\section{Predicting Alarm States}

The literature from 2000 is relatively silent with regard to methods to predict alarm states, the exception being work by Varga, Szeifert and Abonyi (2010) and Nabeshima, Suzudo, Ohno, and

19 Alarm Prevention | Benchmark Research \& Safety, Inc. 
Kudo (2002). The former authors describe the development of a predictive alarm system as it would apply to an exothermic reaction. The latter authors apply the concept to nuclear power. Nabeshima et al. note that the conventional method of nuclear power plant operation that uses a threshold-based alarm system is inferior to a model-based methodology that detects plant faults and anomalies well before alarm set-points are reached. Nabeshima and his colleagues developed a neural-network model of a nuclear power plant using a computerized simulation. The neural network read 22 input variables that through 25 hidden network nodes, yielded 22 output nodes. By comparing the expected state of the plant based on the inputs and the neural network with the actual plant state, the model can detect small deviations in plant functioning before an alarm occurs. The model was trained using 15 different plant states from no- to full-power and 49 malfunctions. The outputs of the neural network were submitted to an expert system that generated directions to an operator.

Using a NPP simulator, the Nabeshima, Suzudo, Ohno, and Kudo (2002) were able to compare the traditional alarm system with that of the neural network/expert system combination. The differences were large. For a small reactor coolant leak during a steady state, the neural network detected a leak as small as a $1 \%$ degradation after approximately 3 minutes. At its best, the traditional alarm system detected a 50\% degradation after 4.5 minutes. During a decrease in power $(2 \% /$ minute), the neural network/expert system detected a small reactor coolant system leak of $15 \%$ degradation in less than a minute. The conventional alarm system detected a 50\% degradation after 6.5 minutes. Technology that provides operators with a more explanatory, comprehensive, and predictive information about the states of a process are likely to reduce the number of alarms.

\section{Alarm Prevention Via Multivariate Representation}

While it is true that every control room operator is actively preventing alarms, the level of success is often dependent on an operator's ability to conceptualize a complex, multivariate, process that is presented via the HMI. Brooks, Wilson, and Thorpe (2004) describe the use of geometric process control, an application of Alfred Inselberg's system of parallel coordinate. The parallel coordinate system allows for the visualization of $n$-dimensional geometry. For the process industry, this representational system allows plant operator to see complex relationships based on measured variables within a process visually. An example of the visual representation is shown in Figure 6 below. Figure 6A shows how 14 different process variables $\left(\mathrm{P}_{1}-\mathrm{P}_{14}\right)$ are related to five different quality variables ( $q 4-\mathrm{q} 8$ ). By using multipoint graphing methods that allow for multiple vertical accesses, the relationship between the process variables and the quality variables can be visualized. When the number of data points is increased, a range of possible variable configurations that yield quality output begins to appear. Figure $6 \mathrm{~B}$ shows 996 data points, each relating process variable measure with quality. The acceptable ranges of quality on each of the quality measures are marked with red triangles. By highlighting all the combinations of the process variables that lead to values inside these limits, it becomes possible to define the parameters of a multivariable process that yield quality results. The yellow lines in Figure 6B show all the variable state combinations that lead to acceptable quality. Operator efforts aimed at 
maintaining the system within the bounds of the yellow lines can increase the likelihood of producing outcomes that fits within the quality boundaries.
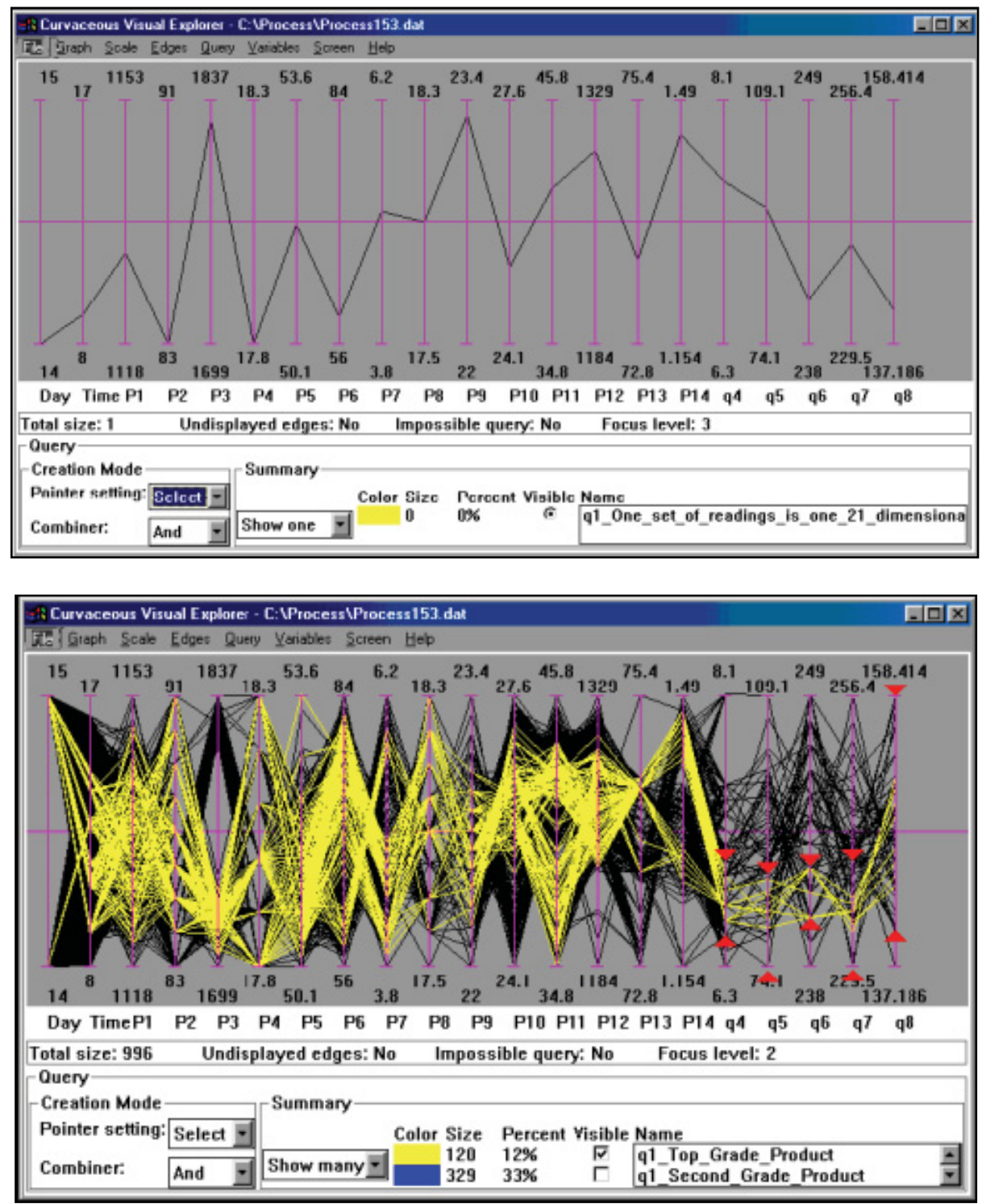

Figure 6 A (above) depicts multiple process variables on a single display. A Shows data from 14 process variables and 5 quality variables at one point in time. B Yellow lines show levels of each process variable that leads to outputs deemed acceptable by the five quality variables.

The ability to conceptualize the complex interactions of process variables gives the operator greater insight into the process and as a result provides the operator with the ability to prevent process alarms. The traditional high-high and low-low alarm limits remain fixed, but the typical high-low alarms can now fluctuate in relationship to the other processes. Because these high-low alarm thresholds are dynamic relative to other steps in the process, the number of false alarms is reduced. This model, applied to a chlor-alkali producer in the UK reduced the false alarm rate from $49 \%$ to $10 \%$ (Brooks, Wilson, \& Thorpe, 2004A, 2004B). 


\section{Alarm Presentation}

Research and development in the area of alarm presentation has been mixed. A number of studies involving the comparison of presentation formats, auto alarm resets, supplemental alarm systems, and auditory alarms propose and evaluate new methods of presenting alarm information. Several studies have conducted heuristic evaluations of existing alarm systems, and at least two propose new alarm presentation methods that have yet to be evaluated.

\section{Alarm Presentation Methods Compared}

O'Hara, Brown, Hallbert, Skraning, Persensky, and Wachtel (200o) conducted an elaborate experiment comparing the effect of alarm display type and the availability of alarm information. (The alarm processing portion of this study is discussed elsewhere in this presentation.) Alarms were displayed in one of three ways: 1) a spatially dedicated constantly visible annunciator panel using a video display unit, 2) via a combination of traditional tiles and a list presented on a video display unit, or 3) integrated into the process display panel and lists present on a video display unit. Alarm information availability was presented in two formats. In the dynamic prioritization condition, high and low priority alarms were presented on separate displays. Low priority alarms were not associated with any audio alerts. In the alarm suppression condition, nuisance and redundant alarms were suppressed and not shown to the operators. The operators had to request this information.

The authors gathered a number of plant and operator related performance measures. The plant related measures were selected in light of the 16 different events that were either low or high in complexity. For operators, the authors compared the performance of two person research operating crews to that of operational experts. Additionally, they gathered data concerning situational awareness, cognitive workload, and operators self-report ratings. The experiment was conducted at the Halden Man-Machine Laboratory (HAMMLAB).

The results for alarm display and alarm information processing were complex. The analyses were characterized by a number of interactions the authors interpret as reflecting the influence of circumstances. In some situations one display performed better than others, but this effect was not constant. Ratings by the operators provided more generalizable insight than the measures of plant or operator performance. When asked to rate their preference of the three alarm display formats, the mixed configuration of traditional tiles with alarm lists was given a most preferable rating 8 out of the 12 times. The preference ratings for the three display conditions are shown in Table 2 below. 
Table 2 Summary of operator preference ratings by display type (O’Hara et al. 200o)

\begin{tabular}{|r|c|c|c|}
\hline & \multicolumn{3}{|c|}{ Preference Ranking } \\
\hline Display Type & Most & Moderate & Least \\
\hline Tile & 2 & 4 & 6 \\
\hline Mixed & 8 & 2 & 2 \\
\hline Integrate & 2 & 6 & 4 \\
\hline
\end{tabular}

With regard to alarm information availability, operators preferred the suppression over dynamic prioritization. Operators participating in the study expressed a desire to have information available in operator-accessible lists rather than having it divided across displays. Preference ratings are shown in Table 3.

Table 3 Summary of operator preference ratings by alarm information availability (O’Hara et al. 200o)

\begin{tabular}{|r|c|c|}
\hline & \multicolumn{2}{|c|}{ Preference Ranking } \\
\hline Alarm information Availability & Most & Least \\
\hline Dynamic prioritization & 2 & 10 \\
\hline Suppression & 10 & 2 \\
\hline
\end{tabular}

The work of O'Hara and his colleagues represents the most sophisticated data gathering effort in the period of reviewed alarm literature. Only one other study gathered data from operators, the remainder proposed modification to alarm displays, without evaluating the impact these modification would have on operator performance.

\section{In Situ Alarm Research}

The last decade has seen four studies examining alarm systems as they are used in process and nuclear power plant control rooms. Three studies (Cullen (2007; Nachreiner, Nickel and Meyer, 2006; Sharhriari, Shee, and Örtengren, 2006) evaluated alarm systems in plants that process oil, chemical, waste water and gas. These heuristic evaluations identified a number of common findings with regard to alarm flooding and interface design. A forth study evaluated the effect of a specialized alarm and information system on operator/system performance and operator acceptance. The results suggest that ancillary safety systems can reduce operator stress while maintaining levels of comparable performance.

\section{Heuristic Evaluations}

Sharhriari, Shee, and Örtengren (2006) conducted case studies of alarm systems in an oil refinery, two chemical processing plants, and a waste water treatment plant. Their analysis of the alarm systems in these plants revealed a series of common problems. Operators in the oil refinery, the waste water treatment facility and one of the chemical processing plants expressed concerns about alarm flooding. None of these aforementioned facilities used any state-dependent alarm 
suppression and as a result operators experienced an excessive number of alarms during plant transients. During these alarm-flood states operators found it difficult to locate the source of the problem. This problem was exacerbated by the small screen space dedicated to the alarm lists. Operators from these plants also reported that the alarms were unclear, confusing, complicated, and that blocked alarms were not shown on alarm displays. From and operations perspective, the authors noted that operators from the oil refinery and both chemical plants relied heavily on onthe-job training to gain the experience and capabilities needed to respond to the alarm system.

Based upon their findings, Sharhriari, Shee, and Örtengren (2006) outlined recommendations for the underlying alarm system, the human-machine interface and the personnel. The recommendations particularly salient for the operation of these systems are summarized in Table 4 below.

Table 4

\begin{tabular}{|c|c|c|}
\hline Alarm System & Human-Machine Interface & Personnel \\
\hline Properly prioritize alarms & $\begin{array}{l}\text { Inhibited or disabled alarms } \\
\text { should be displayed to prevent } \\
\text { them from being overlooked }\end{array}$ & $\begin{array}{l}\text { Optimum staffing levels } \\
\text { should be provided }\end{array}$ \\
\hline $\begin{array}{l}\text { Use logical alarm suppressions } \\
\text { during specific plant modes } \\
\text { and states }\end{array}$ & $\begin{array}{l}\text { Screens should be optimized } \\
\text { to reduce loss of important } \\
\text { information }\end{array}$ & $\begin{array}{l}\text { External distractions to the } \\
\text { operators should be avoided }\end{array}$ \\
\hline $\begin{array}{l}\text { Reduce alarm floods and } \\
\text { increase the salience of } \\
\text { important information }\end{array}$ & $\begin{array}{l}\text { Different control panels and } \\
\text { displays should be } \\
\text { standardized }\end{array}$ & $\begin{array}{l}\text { Operators should be properly } \\
\text { trained and have the requisite } \\
\text { knowledge before working the } \\
\text { system }\end{array}$ \\
\hline $\begin{array}{l}\text { Use clear and identifiable } \\
\text { alarms }\end{array}$ & $\begin{array}{l}\text { Information presented by the } \\
\text { system must be manageable by } \\
\text { the operator }\end{array}$ & $\begin{array}{l}\text { Use simulators for training } \\
\text { skills and building team } \\
\text { performance }\end{array}$ \\
\hline $\begin{array}{l}\text { Incorporate the input from } \\
\text { operators in the specifications } \\
\text { of new alarm systems }\end{array}$ & $\begin{array}{l}\text { Alarm notifications should be } \\
\text { relevant current operating } \\
\text { situation }\end{array}$ & $\begin{array}{l}\text { Operators should possess the } \\
\text { appropriate traits to be an } \\
\text { operator }\end{array}$ \\
\hline $\begin{array}{l}\text { Implement dynamic control } \\
\text { systems }\end{array}$ & $\begin{array}{l}\text { Future systems should } \\
\text { prioritize lists of actions as } \\
\text { well as alarms }\end{array}$ & $\begin{array}{l}\text { User manuals should be easy- } \\
\text { to-use, up-to-date, and } \\
\text { accessible }\end{array}$ \\
\hline $\begin{array}{l}\text { Provide systems to optimize } \\
\text { the alarm system (e.g., expert } \\
\text { systems, etc.) }\end{array}$ & $\begin{array}{l}\text { Future systems should } \\
\text { differentiate cause and } \\
\text { consequence alarms }\end{array}$ & \\
\hline $\begin{array}{l}\text { Alarm should automatically } \\
\text { reset after a fault has been } \\
\text { rectified }\end{array}$ & $\begin{array}{l}\text { Graphically depicted } \\
\text { consequences can be added to } \\
\text { alarm messages }\end{array}$ & \\
\hline $\begin{array}{l}\text { Alarm should clearly inform } \\
\text { operator the reason for alarm }\end{array}$ & $\begin{array}{l}\text { Alarm responses should be } \\
\text { mapped to alarms }\end{array}$ & \\
\hline $\begin{array}{l}\text { Automatic alarm log should be } \\
\text { used }\end{array}$ & $\begin{array}{l}\text { The results of actions should } \\
\text { be communicated to the } \\
\text { operator }\end{array}$ & \\
\hline
\end{tabular}




\begin{tabular}{|l|l|l|}
\hline Alarm System & Human-Machine Interface & Personnel \\
\hline $\begin{array}{l}\text { Alarm masking should be } \\
\text { prevented }\end{array}$ & $\begin{array}{l}\text { Erroneous operator actions } \\
\text { should be reversible if } \\
\text { allowable }\end{array}$ & \\
\hline $\begin{array}{l}\text { Repeating alarms should not } \\
\text { overload the operator even } \\
\text { under severe conditions }\end{array}$ & $\begin{array}{l}\text { The system should inform the } \\
\text { operator of deviations from } \\
\text { safe operating levels }\end{array}$ & \\
\hline Alarms should be prioritized & $\begin{array}{l}\text { Alarms should not be based } \\
\text { solely on color }\end{array}$ & \\
\hline & $\begin{array}{l}\text { Alarms should be augmented } \\
\text { with audible warnings }\end{array}$ & \\
\hline & $\begin{array}{l}\text { Alarm systems should be } \\
\text { designed to promote the } \\
\text { detection of high-priority } \\
\text { alarms and to ensure low- } \\
\text { priority alarms are not } \\
\text { overlooked }\end{array}$ & \\
\hline
\end{tabular}

The authors' recommendations mirror many of the guidelines found in other documents. It is somewhat surprising that the authors only reference EEMUA 191 and no other human factors or alarm system guidelines.

Motivated by the findings of an investigation of a major accident at a chemical processing plant Nachreiner, Nickel and Meyer (2006) conducted a walk through heuristic evaluation of a commercially available process control system used in chemical processing. Their analysis revealed that the system required the operators to memorize the operating and alarm limits for critical functions. Moreover, the interface did not readily supply trend information. Operators had to expand a portion of the display to view trend information effectively occluding the information presented below the area of expanded information. With regard to alarms, the authors noted several shortcomings within the alarm system.

The alarm system in this process controller was largely unstructured. Alarm lists were presented chronologically without prioritization or other alarm processing (e.g., cause consequence filtering). The authors also noted that the alarm system used both English and German words and noted that the use of light letters on a dark background was inconsistent with the system's other displays and with the environment were the system was used.

Nachreiner, Nickel and Meyer (2006) proposed a number of interface modification to address their findings. To create a baseline, they evaluated operator mental workload using $0.1 \mathrm{~Hz}$ heart rate variability and showed that a perturbation within the system increased workload. The perturbation was insidious in nature and none of the research participants detected its presence until the system alarm sounded. The authors contend that a redesigned interface would have allowed operators to detect changes in pressure and avoid the alarm. Although this is a testable hypothesis, the authors did not evaluate any alternative interface configurations. 
Cullen (2007) describes the human factors evaluation of two distributed control systems in place at a gas processing plant in Britain. The analysis revealed issues in several areas including the alarm system. Cullen noted inconsistencies in the alarm prioritization text and alarm color coding. For example, there was inconsistency with which the prioritization terms "high" and "critical" were used. Given the large number of potential alarms, Cullen also noted that there was a potential for auditory overload and recommended that distinct auditory alarms be used to alert operators to the presence of specific alarms.

\section{Other Annunciator Panel Configurations}

Carvalho, Santos, Gomes, Borges, and Guerlain (2008) evaluated the displays of an advanced digital control room simulator that reflected the control room used in the ANGRA I PWR in Brazil. Analysis of the alarm system (see Figure 7 below) incorporated into this simulator revealed a number of shortcomings. The authors noted that the alarm tiles did not support rapid alarm identification, nor did the tiles provide detailed information about the sounding alarm. Because the alarms were divided across two displays, operators had to scan two locations to determine which alarms were activated, the alarm grid was not meaningfully arranged, and the configuration made it difficult to differentiate between alarms of differing importance.

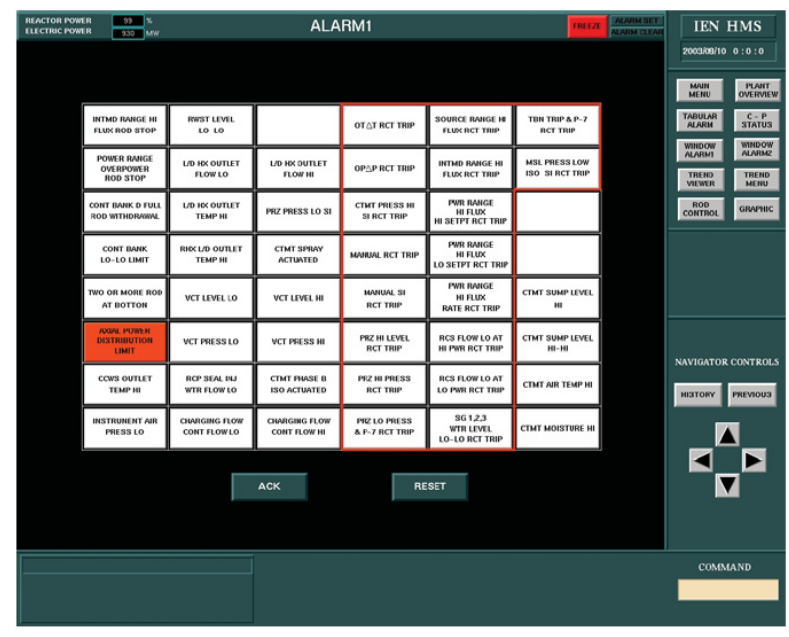

Figure 7 Alarm annunciator from ANGRA I PWR

(Carvalho, Santos, Gomes, Borges, and Guerlain, 2008, p. 279)

Based upon their findings, the authors developed an alarm system prototype to address the identified shortcomings (see Figure 8). The reactor and turbine alarms were divided across two displays, and the individual alarms were organized by the system they represented. Each alarm tile image was used to display multiple alarms. For example, one tile image could be used to represent both a high and low alarm condition. This eliminated the need to present two or more alarm tiles for differing states within the same component. The tile images also allow an operator to acknowledge individual alarms by clicking the active tile image, or acknowledge all sounding alarms by using a universal acknowledge button. The prototype provided trend graphs at the bottom of the display to aid in the diagnosis of the system. The individual alarm tiles were 
designed to serve as links to the affected sub-system's control panel. A red box was used to identify the alarming component within the graphical PID. A corresponding notification was placed on the right margin of the screen. By clicking on this notification, operators gained access to a set of computerized procedures.

In contrast to the original alarm management system, Carvalho, Santos, Gomes, Borges, and Guerlain (2008) addressed many, if not all, of the identified shortcomings with the new prototype. The improvements to the system, however, were limited to the alarm panel interface. The authors did not discuss any alarm management methods (e.g., filtering, cause-consequence, etc.) in their presentation. The prototype appears promising. Unfortunately, the system has not been implemented, nor has it been evaluated as part of the control room simulator.

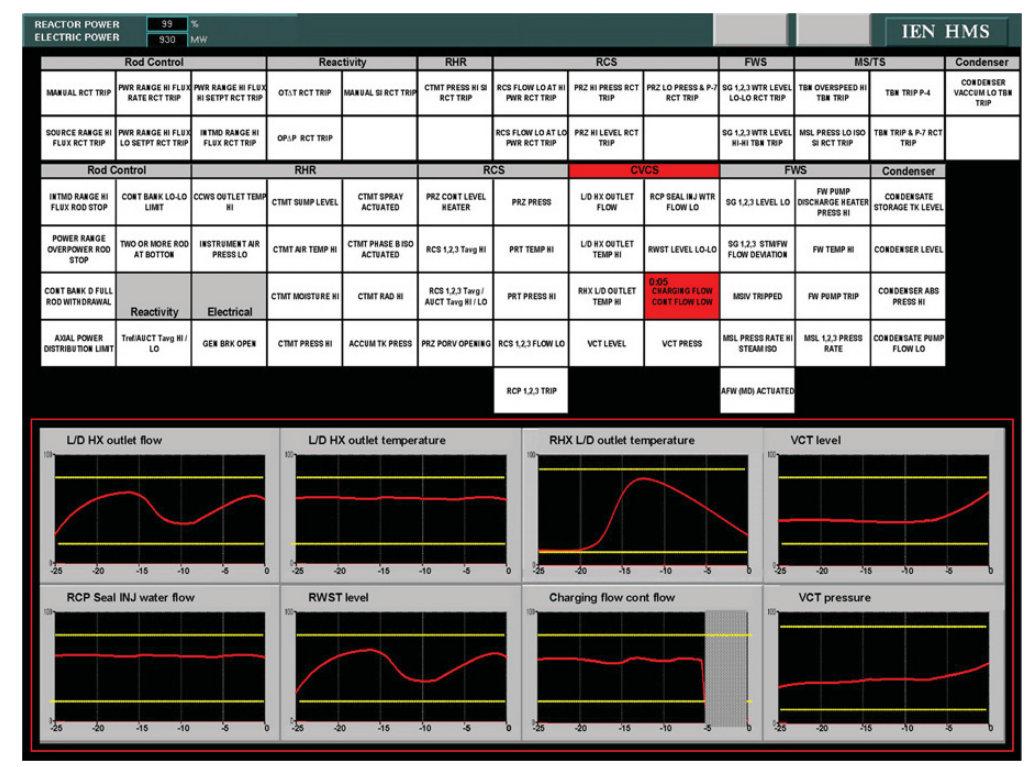

Figure 8 Revised alarm annunciator presented on visual display unit.

(Carvalho, Santos, Gomes, Borges, and Guerlain, 2008, p. 281)

\section{A Supplemental Alarm System}

Norros and Nuutinen (2005) conducted and extensive multi-dimensional analysis of a new Safety Information and Alarm Panel (SIAP) introduced into a full-scale nuclear power plant control room simulator. Working in conjunction with the OECD Halden Reactor Project, the two authors developed and implemented a sophisticated data collection paradigm that examined the effect of the SIAP on the work practices and the experiences of six four-person crews that managed four scenarios characterized by faults in the system. The SIAP was designed to aid plant operators during accident situations by providing an overview of the plant and to aid operators in the use of emergency procedures. Results of the study are complex. The analyses of work practices suggest that this augmenting system affected crews and individual crew-members differently. With one exception, all of the research participants reported feeling less stress when working scenarios with the SIAP. According to the authors, "This effect was due to the system's ability to bring out the most important information available (p. 350)." 
The results also revealed that the system had a differential impact as a function of the system fault. In less complex and transparent situations, the SIAP was deemed beneficial. This was not the case in for more complex situations where the authors could not detect any differences. Overall, the SIAP did not significantly affect the combined operator/system performance, a positive finding when considered in the light of reduced operator stress. The results suggest that similar levels of operator/system performance can be obtained with a smaller investment of human resources (e.g., cognitive workload). Additionally, the results point to the potential value of information and alarm systems that provide operators with the ability to quickly obtain overview information and alarm response aids.

\section{Use of Peripheral Alarms}

As is discussed in the section on alarm system guidelines, the telecommunications industry is in a decidedly different stage of development when compared to the nuclear or chemical processing industries. Despite these differences, there are still opportunities to learn from efforts used to better manage alarms in the telecommunications industry. Italian engineers Angelucci, Di Paolo, and Tarantino (2009) propose a taxonomy for the classification of alarm and system information that is based on the extent of Interruption, Reaction and Comprehension (IRC) demands placed on an operator. This taxonomy is used to prioritize alarms. A critical alarm that distracts the operator from the primary task, requires an immediate response, and requires long-term comprehension would be characterized as $I=1, R=1, C=1$ or 111.

Angelucci and his colleagues map the combinations of I, R, and C in two-dimensional space defined by continuums of attention and awareness (see Figure 9 below). The authors classify alarms that are characterized by low interruption, low reaction, and high comprehension (oo1 alarms) as ambient, requiring lower levels of attention and awareness. They even suggest that this information be perceived at or below the threshold of awareness (i.e., subliminally) see Figure $9 \mathrm{~A}$. Because these alarms are presented in the peripheral field of view, the authors suggest that the alarm tile be slowly animated to increase saliency and draw the attention of the operator. Critical alarms (i.e., 111) should be presented in a manner that attempts to interrupt the operator and continues to do so until the operator responds (see Figure $9 \mathrm{~B}$ ). 


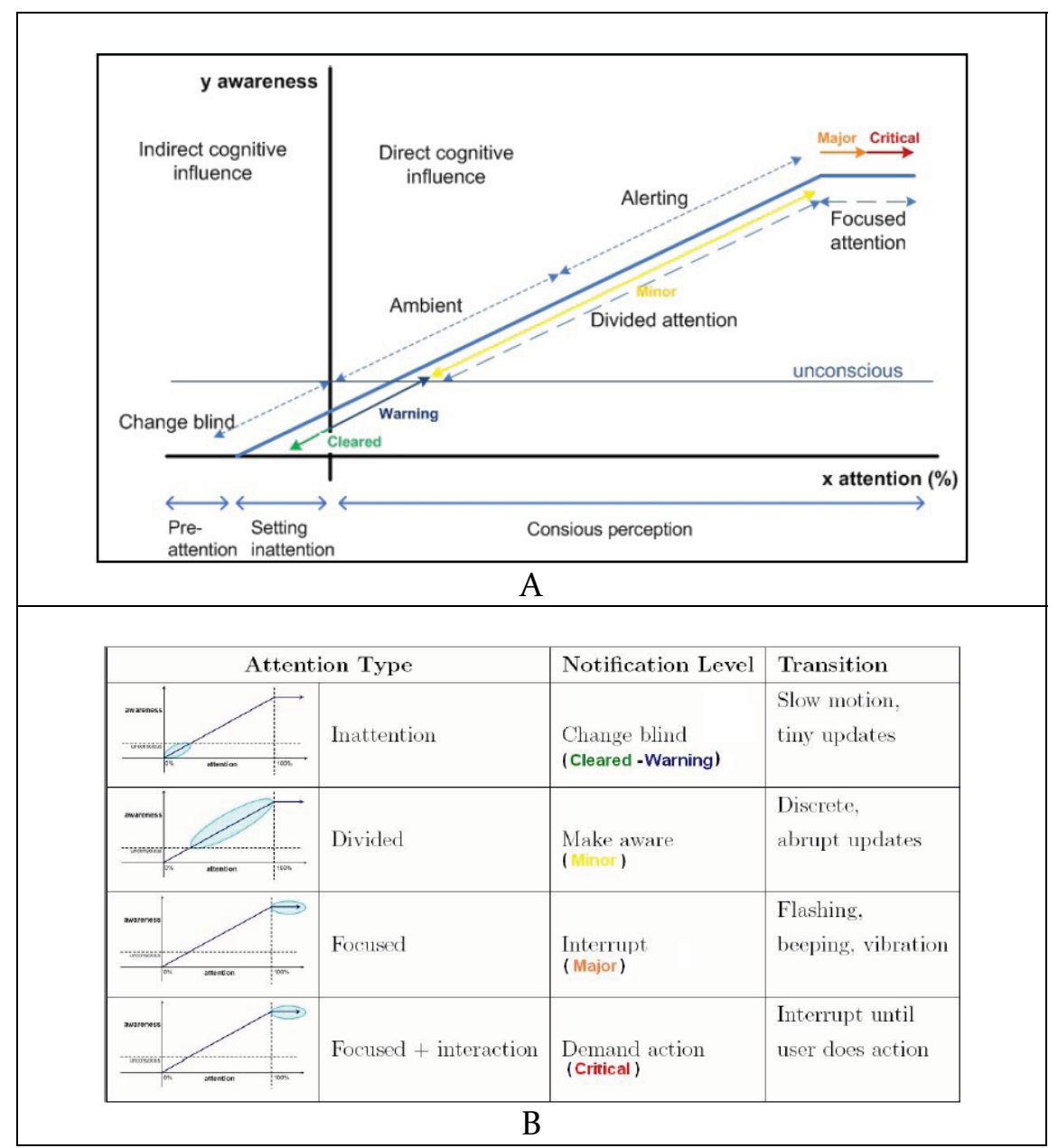

Figure 9 A Plot of alarm priorities along continuums of attention and awareness. B. Alarm transition type as a function of notification level Angelucci, Di Paolo, and Tarantino (2009), p. 244, 245.

Concerning the presentation of the alarm itself, Angelucci and co-authors suggest using a multifeatured display that depicts the date and time, the priority of the alarm, the affected network element, and information concerning the cause and location of the fault. They suggest that multiple alarms could be represented on the same alarm display. Figure 10 A shows the proposed alarm display layout and $9 \mathrm{~B}$ shows how multiple alarms might be represented.

Although the perspectives of the telecommunications industry differ from those that would be consider as possessing significant hazards to human life, these perspectives provide a unique view of how others are attempting to address the need to notify human operators of conditions that require their intervention. Angelucci's et al. taxonomy and presentation method were crafted using human attention, awareness, and comprehension as guides, and as such, suggest that validation studies are warranted. Unfortunately, like other studies that propose alternative alarm 
presentation methods, Angelucci and colleagues did not provide any data relative to how humans would interact and perform with their proposed system.

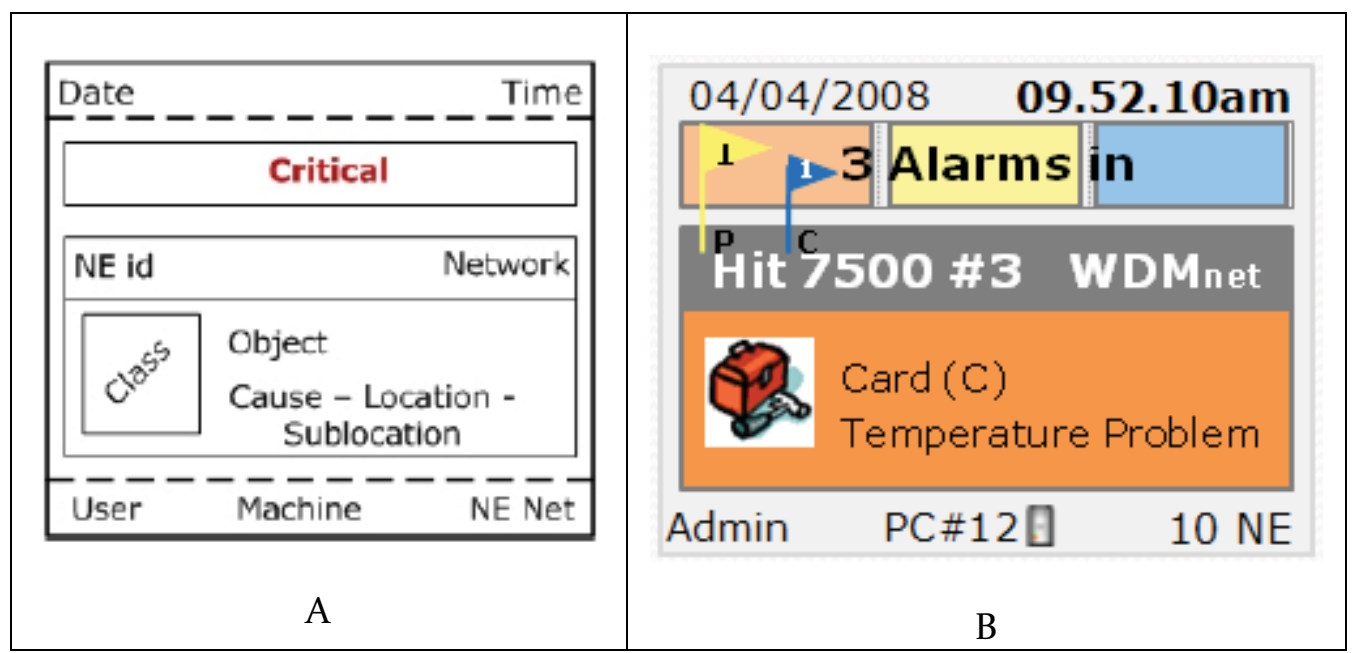

Figure 10 A Proposed alarm display layout and contents. B. Presentation of multiple alarms in a single alarm display ( Angelucci, Di Paolo, \& Tarantino, 2009, p. 243, 245).

\section{Automatic Alarm Reset}

Taiwanese researcher Huang and his colleagues (Huang, Hwang, Yenn, Yu, Hsu, \& Huang, 20o6; Huang, Lee, Hwang, Yenn, Yu, Hsu, and Huang, 2007) examined the effect of automatic alarm reset on the workload, situation awareness, and operation times of operators. Performance for experts (nuclear power plant operators) and novices (students) was compared for three different scenarios: load rejection (Huang et al., 2007), integrated operating procedure, and abnormal operating procedure. The operation times for novices and trained operators did not differ significantly for the automatic reset condition, but it did in the manual reset condition. Operation time was defined as the total time operators spent in decision-making and action. The end of this interval was defined by the return of all alarms to a normal state. For the load rejection task, operation time was significantly shorter in the automatic than the manual reset condition. Comparison of the situation awareness data showed no significant differences in ratings as the result of the reset condition. Finally, measures of workload revealed that novices reported higher levels of effort, a subscale of the NASA TLX, when using an auto-reset alarm when compared to the manual condition. Additionally, these novice participants reported higher levels of performance workload (another subscale on the NASA TLX) in the manual condition, when compared to the trained operators. These differences were further evaluated in a second study.

This follow-up experiment used participants that attended a 96-hour training course in the operation of an advanced boiling water reactor. The authors presented the two alarm reset conditions in combination with two levels of alarm load, 5 and 10 alarm signals. Analysis of the resulting operation time and workload data did not reveal any significant differences. The 
situation assessment data did reveal a significant difference; however, the authors did not indicate its direction.

The trained operators in Huang's et al. (2007) study provided three recommendations for the use of automatic reset alarms:

- The alarm history should be displayed in real-time or within 3 seconds

- Enhance the way to display the return-to-normal alarms

- Support for a manual reset mode on the alarm system

Huang's et al. (2006) study was similar to his later work, except that it used different tasks. In the study published in 2006, Huang et al. evaluated the effects of automatic alarm reset on an integrated operating procedure and an abnormal operating procedure using 30 novice participants. The dependent variables included a binary measure of task completion, mental workload as measured by the NASA TLX, and a measure of comprehension. Comparison of these dependent variables across the two reset conditions revealed only one significant difference. The effort subscale on the NASA TLX showed significantly different ratings across the two reset conditions. Unfortunately, the authors did not indicate the direction of this difference.

Huang et al. (2006, 2007) acknowledged that auto-resetting alarms represent a departure from current operating practice in Taiwan. Although the two studies are small, the results do not provide any clear performance, workload, or situation awareness evidence that would prevent further study of how auto-resetting alarms might be used as part of a larger alarm management system.

\section{Auditory Alarms}

Alarms are often presented in conjunction with an auditory component that is designed to draw an operator's attention to a condition that requires operator intervention. Contemporary alarm guidelines discuss, in varying levels of detail, how the audio component of an alarm should be presented. For example, NUREG-o7oo states that the intensity of an auditory alarm signal should be $10 \mathrm{~dB}(\mathrm{~A})$ above the ambient noise. Peryer, Noyes, Pleydell-Pearce, and Lieven (2005) surveyed 50 pilots to determine their reaction to audio alarms in aircraft cockpits. Results of the survey showed that approximately half of the respondents reported experiencing alerts that impaired their performance, a phenomenon noted earlier by Thackray and Touchstone (1970). One respondent reported, "When the audible caution/warning is so loud it startles me, it just adds more distraction/confusion when I probably have more than I need. Silencing the loud noise temporarily takes precedence over (1) good flying, (2) analyzing the problem, and (3) solving problems" (p. 242). Half of the survey respondents said that the alerts were too loud.

Three-quarters of the respondents reported experiencing a startle response from an auditory alarm. Instantaneous increases in sound pressure are associated with the startle response, which itself is associated with sympathetic physiological changes. Sixty-four percent of the respondents expressed a preference for combination alarms that combine an auditory alert with a speech 
element. These combination alarms pair an auditory alert tone that is followed by a spoken message. Earlier research has shown that the intensity, pitch, and pulse interval can be manipulated to affect perceived levels of urgency (Burt, Bartolome, Burdette, \& Comstock, 1995; Haas \& Casali, 1995; Haas \& Edworthy, 1996; Hellier \& Edworthy, 1999; Momtahan, Hétu, \& Tansley, 1993).

\section{Auditory Alarm Designs}

Catchpole, McKeown, and Withington (2004) note that auditory alarms can serve many different purposes. An auditory alarm can convey information about a fault in a particular system, a quality they term the "what" of an alarm. The auditory alarm can also convey information about the locale of an event, the "where" quality, and the alarm can convey information about the urgency, the "when" Pure tone signals, for example, can be related to specific alarmed events. The "where" or localization qualities of the signal can be conveyed by increasing the frequency spectrum of the signal. Finally, the "when" or urgency information can be communicated using different pulse rates and auditory frequency patterns. These qualities, however, often conflict. For example, a narrow spectrum tone used to convey "what" can reduce the localizability or "where" information and broad spectrum noise, while improving localizability, can mask the "what" information. To address these inopportune interactions, the authors created and evaluated complex tones that promote all three qualities.

Localization is sound is dependent on interaural timing, the difference in time when a sound reaches each of the ears, interaural level differences, and the effects of the human head (e.g., the head itself and the outer ear) on the sound, called the head related transfer function (Catchpole et al., 2004). Based on prior research Catchpole et al. set the levels of these qualities to optimize localization. Broadband signals:

- Less than $1500 \mathrm{~Hz}$ promote the use of interaural timing

- Greater than $3000 \mathrm{~Hz}$ promoted detection of interaural levels

- With content up $1014 \mathrm{kHz}$ provides cues resulting from head related transfer functions.

A signal of these qualities can be easily localized, however, the stimulus alone would mask any tone used to define the "what" message. Catchpole et al. divided the signal's spectrum to create a noise-free notch into which a tone was inserted. Two different noise-notches were created, one between $1-3 \mathrm{kHz}$ and one between $1-10 \mathrm{kHz}$. In these two noise free portions of the spectrum, the authors inserted one of three different tones, an upsweep tone from 1 to $3 \mathrm{kHz}$, a down sweep from 3 to $1 \mathrm{kHz}$, and a $2 \mathrm{kHz}$ pure tone. The localizability of these three complex signals was compared to that of simply white noise which has been shown to have the greatest localizability. Results of the localization experiment showed that the performance of the research participants in localizing the sound of the low frequency complex spectral notch signals were comparable to that of white noise, strong evidence that broad spectrum noise can be used for localization and a tone can be imbedded in a low frequency notch to convey specific information. Catchpole and his 
colleagues continued the study of these complex signals by altering the tone to evaluate changes in perceived urgency.

Three different types of signal tones were embedded within the $1-3 \mathrm{kHz}$ noise-free notch in the signal: a five harmonic complex tone, an up sweep tone, and a down sweep tone. The ratio of noise to tone was also manipulated. In one condition the ratio was high (high tone with low noise) and in the other the ratio was low (low tone with high noise). These signals were presented to research participants who rated the level of perceived urgency using a modulus-free magnitude estimate technique. The sweep conditions were perceived to be more urgent than the complex tone condition. Catchpole et al.'s work demonstrates that there can be more to an auditory alarm. By systematically defining the intent of an alarm, designers can convey at least three types of information in a single signal.

Writing for the medical community, Edworthy and Hellier (2006) provide a brief overview of the alarm literature prior to 2000. They write, "The main problems found with alarms are that they can often to be loud and shrill (because they are usually installed on a 'better-safe-that-sorry' logic) with the risk that they are turned off because they are so irritating, there are too many of them, they are often difficult to tell apart from one another and there are usually too many false alarms for the system to be trusted by the user"(p. 12). Citing research conducted at a Canadian hospital (Momtahan, Tanslet \& Hetu, 1993), Edworthy and Hellier point to the continuing need for auditory alarms to have substantial meaning. In the hospital study, Momtahan et al. found that alarms used in the intensive care unit were understood by fewer than half of the clinical staff.

To promote the comprehension of auditory alarms, Edworthy and Hellier (2008) encourage the development of auditory alarms that are readily understandable. Speech incorporated into an alarm is likely the single best way of increasing understandability. If speech cannot be used, the authors suggest that auditory icons can be used. An auditory icon are alarm sounds that are related to the functions they are to represent. For example, a pump failure could be associated with an alarm that sounds like a pump decreasing in speed when it is no longer energized. Although the authors do not provide data in the reviewed paper, their conclusion that speech and auditory icons are more readily interpretable seems appropriate when the language is understood and operators have sufficient experience with the sounds associated with the processes they manage. The application of sound can be broadened beyond that of alarms. Edworthy and Hellier suggest that data can be sonified, a process called sonification. Using variables such as pitch, intensity, speed, and harmonic content, sound can be used to represent a process or state that can be monitored via the sound it generates. 


\section{Alarm Guidelines}

The decade since the beginning of 2000 has seen the development and promulgation of numerous alarm guidance documents by groups within industry, standards organizations, and regulatory agencies, and include:

- $\quad$ The Alarm Management Handbook (Hollifield \& Habibi, 2006)

- EEMUA 191: Alarm Systems: A Guide to Design, Management and Procurement ${ }^{\text {nd }}$ Edition (2007)

- ASM Consortium Guidelines: Effective Alarm Management Practices (Errington, Reising \& Burns, 2009)

- ANSI/ISA - 18.2 - 2009: Management of Alarm Systems for the Process Industry (2009)

- $\quad 3$ GPP TS 32.111-1 V9.0.0 $3^{\text {rd }}$ Generation Partnership Project; Technical Specification Group Services and Systems Aspect; Telecommunication management; Fault Management; Part 1: 3G fault management requirements (Release 9) (2009)

- Alarm Management Information Base (MIB), RFC3877 (Chisholm \& Romascanu, 2004)

- Advanced Control Room Alarm System: Requirements and Implementation Guidance (EPRI, 2005)

- Alarm Processing Methods: Improving Alarm management in nuclear power plant control rooms (EPRI, 2003)

- Better Alarm Handling (HSE, 200o)

- Human-System Interface Design Review Guidelines (NUREG-0700, 2002)

- Advanced Alarm Systems: Revision of Guidance and Its Technical Basis (NUREG/CR6684) (US NRC, 2000)

There are many similarities among the various guidance documents. The differences, in part, reflect differences across the industries and what might best be described as their developmental status. A review of an alarm system within the telecommunication industry by Wallin (2009), suggests that the telecommunication industry is at an earlier stage of alarm philosophy development when compared to processing industries. Wallin reviewed the existing telecommunication alarm management related guidelines and concluded that the industry had yet to agree upon a definition of an "alarm." His analysis of an alarm database at a large telecommunications company revealed 15 million alarm notifications from 3.5 million alarms and 90,ooo associated trouble tickets. Using the trouble ticket as the criterion for a "valid" alarm, Wallin concluded that only $2.5 \%$ of the alarms were truly states that required human intervention. The uncertainty of what constitutes an alarm is reflected in the industry's guidelines.

Chisholm and Romascanu's (2004) guide on alarm management within telecommunications defines an alarm as a "persistent indication of a fault" (p. 4). Similarly, the 3 GPP guideline defines an alarm as "abnormal network entity condition, which categorizes an event as a fault" (p. 8). As Wallin found, these broad definitions have created an unmanageable alarm condition within the telecommunications industry. When less than $1 \%$ of the alarm notifications require human 
intervention, it is obvious that further development in the area of alarm philosophy could benefit the telecommunications industry.

The developmental state of the alarm domain within telecommunications might simply reflect fundamental differences between it and its counterparts in petrochemical or nuclear power. Failure of a $3 \mathrm{G}$ communications component might have less severe consequences than failure of a pressure vessel within a chemical processing facility or a reactor cooling pump. Regardless of the industry, service quality, output, and efficiency all deteriorate during periods of equipment or process malfunction or degradation.

\section{Reaching the Right Audience}

Meaningfully comparing the guidance documents is somewhat challenging (cf. Thunberg \& Osvalder, 2007). A side-by-side comparison of the contents in these documents reveals considerable overlap in some areas. Some guidelines cover elements with the domain in greater detail than others, while others are silent on some topics. Unfortunately, none provide comprehensive coverage of the alarm domain. NUREG-070o, for example, provides detailed HMI guidance but is largely silent on the topic of alarm philosophy and rationalization. Conversely, Hollifield and Habibi's (2010) comprehensive guide builds alarm systems from a well-defined alarm philosophy and rationalization, yet treats the HMI component lightly. The variety of guidance documents reach different audiences with varying levels of detail.

EEMUA 191 and ASM Consortium Guidelines provide high-level alarm domain information. Both are written for a management audience that has responsibilities in the design, development, and procurement of systems. Two-thirds of EEMUA 191 is comprised of appendices that cover a variety of topics ranging from alarm presentation techniques (e.g., alarm lists) to data collection surveys that can be used to collect operator data. In contrast, the ASM Consortium Guidelines presents its readers with a high-level prioritization scheme that gives alarm designers a hierarchy of guidelines that should be considered. Both guidance documents provide high-level examples of different alarm structuring methods and provide sufficient information to allow a system designer to work with a vendor of alarm management systems.

ANSI/ISA-18.2, IEC 62241, and NUREG-0700 are more consistent with traditional design specification documents. Guidance from ANSI/ISA covers a broad range of topics ranging from alarm philosophy to alarm presentation and alarm validation and reliability. In contrast, NUREG and IEC guidance only infers higher-level alarm philosophy requirements. Of the three documents, the IEC provides the most general information with regard to the design of alarm systems. NUREG-070o presents the highest level of resolution, with the ANSI/ISA standards somewhere in between the two. Some of the guidelines in the NUREG are referenced, adding resources not available in other guidance documents which tend to provide few references to specific guidelines. Guidance from these three documents is targeted more toward the system engineer or designer than to management. 
Guidance from EPRI (EPRI 2003, 2005) and the US NRC (NUREG/CR-6684) are more akin to technical reports than specific design guidance although all three have specific design recommendations. All three documents review the extant literature and NUREG/CR-6684 findings were used to update the first version of NUREG-07oo. Guidance from the US NRC differs from that produced by EPRI in that it provides a technical basis from which design recommendations are made. Moreover, the NRC documents extend the literature review process to the original research level. In contrast, the EPRI documents use other summaries and guidance documents as their primary sources. Despite differences in source material, guidance provided by EPRI and the NRC might best be suited for the system designer or analyst than management.

\section{Human Response to Alarm}

The following section contains a review of published research regarding response characteristics, biases, strengths and weaknesses that human beings exhibit in complex control environments such as the nuclear power plant control room. The review begins with a number of studies that take a classic signal detection approach to system design and operator performance. Many of these studies found that both the control room and individual operators' performance are well described by the signal detection model, especially when unreliable alarms are present. In essence, they found that operators quickly learn the reliability of a given alarm and adjust their trust and prioritization to match its reliability. As operator trust stabilizes, the system begins to run more smoothly, which leads to fewer false alarms and results in a net overall gain of sensitivity for the control room as a whole.

The review then explores efforts aimed at increasing operator trust by various alarm preprocessing methods that result in fewer false alarms in the control room, again leading to an increase in operator and control room sensitivity to plant conditions. The advantage of several of these methods is that they amount to independent software bypass filters that can be integrated into existing control rooms without physical modifications to the plant or control room.

Several publications that investigate human capabilities and limitations when processing alarms in a complex, multi-alarm environment are presented. Topics such as mental workload, attention span, proximity and recruitment of contiguous alarms, cognitive tunneling, alarm trust and prioritization, and scheduling of alarm responses are covered in this section.

Research into control room design wraps up the human response literature review. Several studies looked at strategies and other methods human operators used to complement or improve on control room design, including a comparison of strategies used in analog and digital control rooms. Overall, they found that because the underlying physical process and the human operators remain the same, most of the strategies of the analog control room were apparent in the digital. They did note, however, one new limitation specific to the digital control room. Keyholing is the workstation equivalent of cognitive tunneling and should be better understood and compensated for as digital control rooms continue to be designed and implemented. Also 
included in this section are several publications that recommend improvements or improved tools for use in the control room design process itself.

\section{Signal Detection, Workload \& False Alarms}

Signal detection theory considers the response to a signal to have two components - sensitivity and response bias (SDT, Swets, 1996). Sensitivity refers to the trigger threshold of a perceiver, in this case, an alarm sensor. Response bias refers to an internal limit that an operator chooses before he will react to a signal (e.g., an alarm). SDT allows an analyst to isolate the human components of responding to an alarm independent of the incoming signal. SDT classifies alarm responses as one of four types: correct reaction to a true alarm, incorrect acceptance of a false alarm, missed true alarms and wrongly accepted false alarms. The bulk of cases fall into correct responses to true alarms and incorrect acceptance of false alarms. However, some true alarms will be misclassified as a false alarm and some false alarms will be accepted as a true event. In SDT scenarios, the goal is to maximize the correct responses to true alarms, reject all false alarms, and reduce the occurrence of errantly rejected true alarms as much as possible. It is also beneficial to avoid spending resources responding to false alarms.

When placed in an SDT scenario, such as monitoring and controlling complex industrial processes, human beings adapt to their environment. In particular, they adjust their response bias to match the monitored system properties. In a system with low reliability and a high false alarm (FAs) rate, operators adjust their behavior to ignore or delay responding to the alarm and may seek or wait on confirmatory information before acting. While reasonable, this strategy comes with an increased risk of missing or delaying a reaction to a genuine alarm event. Similarly, in a system with high reliability and few false alarms, operators shift their response bias so that they react quickly and with confidence in the alarm. This also comes with a cost, however, in that this strategy will spend resources chasing more false alarms. Put simply, human operators develop an understanding of, and trust in, an alarm's reliability and adjust their actions accordingly.

Bustamante, Bliss \& Anderson (2007) used SDT to understand how plant operators shift their response biases based on alarm reliability or trustworthiness with the goal of maximizing the response to true alarms, minimizing the loss of resources on false alarms and keeping the number of missed alarms to a minimum. They monitored participants' adjustment to mock alarm systems with varying degrees of reliability. They also varied the operator workload to examine if that affected the operator's response bias. They found that operators responded the quickest to alarms with high reliability and when they were under low workloads. They also found that operators took longer to respond or ignored it all together when the alarm was unreliable and when workload was high, suggesting that when the operator is busy, they are more likely to conclude that a high false alarm rate system is 'crying wolf' (Breznitz, 1983). The 'cry wolf' phenomenon has been directly studied by Bliss and Dunn in 2000.

Bliss \& Dunn (2000) examined alarm reliability, perceived alarm reliability and operator trust in a further exploration of the 'cry wolf' effect (Breznitz, 1983), that is, alarm mistrust. Following up 
on previous research into alarm mistrust, the authors note that operator trust in an alarm can be manipulated by external information such as signs or statements as to the alarm's reliability (Bliss et al. 1995), that operators given reliability information made more frequent responses, but operators given alarm validity information made more appropriate responses (Bliss et al., 1996), and that increasing the urgency of alarms increased the operator's response rate, independent of the operator's perception of alarm reliability, but perhaps at some cost to reaction time (Bliss, et al., 1995).

The general thrust of Bliss and Dunn (2000) was to examine the implications of mental workload on alarm mistrust, specifically, on whether alarm mistrust becomes more prevalent in high mental workload scenarios. Using a complex display depicting an active monitoring and flow adjustment process control, Bliss and Dunn (2000) found that high mental workloads (more tasks or more frequent events to monitor) produce longer reaction times and less accurate and less frequent responses. Similar to Bustamante, Bliss \& Anderson (2007), they also found that the trust in a partially reliable alarm decreases under high mental workloads. The overall conclusion is that in complex multitasking environments, alarm reliability becomes more salient in that the operator will allocate less time to an unreliable alarm and will respond slower if at all. One method to compensate for this, besides improving the alarm's reliability, is to give more lead time to alarms when the operator's mental workload is high (e.g., during NPP operational transitions or during malfunctions). The role of workload was more directly addressed by Cummings and Guerlain (2007).

Cummings \& Guerlain (2007) examined operator workload in the context of managing multiple autonomous processes (Tactical Tomahawk missiles, which can be re-aimed in flight). Similar to NPP operators, autonomous vehicle (AV) operators monitor and adjust the characteristics of multiple subsystems (individual AVs) in demanding, noisy and stressful environments. Cummings \& Guerlain (2007) estimated workload as 'operator busyness' - the proportion of time the operator was engaged in gathering information or controlling the AVs. For AVs, they found an inverted $U$ function (aka the Yerkes-Dodson law). Inverted $U$ functions refer to phenomenon where performance rises steadily with some other factor but reaches a peak and declines as the other factor continues to increase. For example, some coffee will increase manual dexterity but as too much caffeine is ingested, manual dexterity begins to decline.

Cummings \& Guerlain (2007) found that above or below a comfortable number of events, the operator's performance fell off. For AVs, operators performed best when their busyness was around $50-60 \%$ busy time, but that above $70 \%$ busy time, performance dropped off. This has some bearing on the design of NPP control rooms in that it highlights the importance of matching the workload to operators' capabilities. Too few alarms and the operators get bored, their attention wanders and they pay a cost in reaction time as they reorient to the system. Too many alarms, and the operators begin to prioritize or ignore subsequent alarms, experience cognitive tunneling or exhibit other coping mechanisms any or all of which ultimately reduce their performance. 
Meyer (2001) proposes that good system design depends on system specific characteristics and operator characteristics. There is no one size fits all design standard for NPP control rooms. Instead there are general principles that should be understood, controlled and optimized in every control room. Taking an SDT approach similar to Bustamante, Bliss \& Anderson (2007), Meyer (2001) looks at the 'cry-wolf' phenomenon (Breznitz, 1983) as an operator gains experience over time. According to Meyer, previous research failed to separate alarm system sensitivity from operator response biases and may have missed or misrepresented operator performance.

Meyer (2001) found that operators adjust their trust in a partially reliable alarm as they gain experience, initially always responding to the alarm but ultimately matching their response rate to their trust in the alarm, which is derived from their perception of the proportion of the number of times the alarm was correct. In a second experiment that examined alarm proximity to alarm trust, they found that operators still learned to ignore an unreliable alarm, but that it was more difficult to do so when the alarm was integrated with other related system information. They also noted some decrease in correct alarm response when the alarm was highly reliable, suggesting that perhaps operators never fully trusted the reliable alarm and double checked other indicators some proportion of the time.

In general, Meyer (2001) reports that the participants relied on the warning initially, learned the difference between valid and invalid warnings quickly and adjusted their response rate, but never completely excluded the unreliable warning information. The author concludes with a discussion of automation bias - the tendency to trust the alarm system too much. In automation bias, there are two types of trust exhibited by operators: compliance and reliance. In compliance, the operator trusts alarm and reacts when it sounds. The contribution of the current article is that compliance declines as the operator shifts to a probability matching strategy, allocating trust based on his experience with the alarm's reliability. Compliance tends to be exhibited in hazard warning systems - the alarm sounds when something is wrong and the operator needs to do something to rectify the situation. Reliance refers to an operator's tendency to trust and rely on System OK messages, that is, they rely on the system's report that things are well (e.g., a green light or absence of an alarm), often to the exclusion of contradictory or other information of concern. Both type of automation biases can lead to reduced value of having a human supervisor of an automated process alarm system and should be addressed through training and monitoring.

\section{False Alarms in Aviation \& Maritime Applications}

Looking at the US aviation industry, Bliss (2003) examined the alarm related incidents reported by civilian and US Army pilots. Incidents reported to the NASA's Aviation Safety Report System (ASRS), the NTSB, and the US Army Safety Center that involved alarms were reviewed and categorized according to alarm condition: true, false, missed, or unknown, and reported cause. The results of this categorization process were compared to those reported earlier by Tyler, Schilling, and Gilson (1995). Incidents involving alarm that were reported to the NTSB, US Army, and the US Navy were comparable with 1.1\%, 3.0\%, and 5.0\%, respectively. Bliss found that $27 \%$ of incidents reported to the ASRS, a reflection of the emphasis on human factors in this reporting system. For incidents reported to the NTSB and ASRS, the largest proportion of alarm- 
related incidents was associated with what Bliss termed "true" alarms with $60 \%$ and $58 \%$, respectively. The proportion of false alarms was not inconsequential. For the NTSB, $20 \%$ of alarm-related incidents were associated with false alarms. For ASRS this percentage was $28 \%$, and for the US Army the false alarm rate was 90\%.

In a maritime application, Kerstholt and Passenier (2000) studied the effect of false alarms on the behavior of maritime students tasked with monitoring simulated navigation, propulsion, power generation and cooling tasks. Earlier work by Kerstholt, Passenier, Houttuin, and Schuffel (1996) showed that poor response to similar maritime tasks was attributable to poor knowledge of the system and tunnel vision. This more recent work considered the effect of false alarms on the performance of research participants as defined by:

1) The number of auto-shutdowns which occurred when the situations that were not solved in the allotted time

2) The number of incorrect resets of equipment directly responsible or tied to the system with a fault

3) The time needed to detect a fault, structure or gather data about the fault, and diagnosis or solve the fault

Research participants completed the simulated task in either the false alarm or no false alarm conditions. In the false alarm condition, participants received 24 faults half of which were false. In the no false alarm condition, participants received 12 faults and no false alarms.

Comparisons of these three performance measures revealed dramatic effects of false alarms. Participants in the false alarm condition experienced significantly more automatic shutdowns and took more time to diagnose the faults than their no false alarm counterparts. There was no difference in the number incorrect resets but an examination of the information seeking behavior revealed that participants in the false alarm condition sought information less frequently during the detection and diagnosis phases of their responses. The results provide evidence that false alarms affect information gathering and problem solving behavior. Kerstholt and his colleague suggest that false alarms affect the arousal level of the participants which is reflected in the performance data.

\section{Alarm Conditioning}

Bock, Brotherton, Grabill, Gass, and Keller (2006) apply the SDT model to system component maintenance alarms to develop more sophisticated methods to predict when a physical component will need replacement. Most component replacement schedules are simply time based, using either time since installation or run time to schedule component replacement. A more sophisticated, and possibly less costly approach, is conditioned based maintenance (CBM). For example,, most people replace their car oil filter after a certain number of miles driven (run time) but replace their tires based on their condition (CBM). 
Bock et al. (2006) developed a complex algorithm-based alarm system for component health around the logic of hazard curves. Hazards curves show the probability of a component's failure given how long it has been in service. Developed by life insurance companies to forecast health care liability, the original hazard curves described the likelihood of a person dying given their age. A simple, and less macabre, hazard curve example is light bulbs. Given that a light bulb has lasted 90\% of its intended service life, what is the probability that it will fail in the next interval? This is tantamount to replacing a component simply based on its age. Another example of a commonly known hazard curve used by industry is MTBF - Mean Time Between (component) Failure.

Building on the original hazard curve, insurance companies developed increasingly complex hazard curves for different health and living conditions. For example, modern insurance hazard curves take diet, activity, tobacco and alcohol use, genetics and a host of other factors in addition to age to better predict life span and potential health expenditures. Bock et al. (2006) extended this logic to component replacement alarm systems using CMB. To improve fault prediction, the authors developed a complex minimum-volume hypersphere. In essence, the hypersphere is a trainable, multidimensional cluster analysis that can separate incoming alarm events in to normal, known faults and unknown, novel faults. Because the hypersphere cluster is trainable, it can be used to reduce false alarms by passing novel events on to the operator and simply logging known fault types. In testing, they demonstrated that the hypersphere algorithm did indeed result in an increase in alarm reliability, which resulted in alarm mitigation or sanitation (Larsson, 2000).

Although not directly noted in the article, the hypersphere algorithm is designed to be slipped in between the alarm sensor network and the control alarm, effectively allowing a way to achieve a considerable measure of alarm sanitation and mitigation without changing the physical components of the NPP. In effect, it becomes a simple processing unit at the end of the incoming data stream and could be used widely and flexibly with little installation or operating costs beyond the initial tuning.

Liu and Su (2006) tested a similar adaptive algorithm-based alarm mitigation system to improve alarm reliability. Noting that humans adjust their trust in an alarm based on the proportion of true to false alarms, they developed a trainable fuzzy logic system that adjusts the alarm alert criterion based on dynamic system trends, just as humans do. The overall goal was to reduce loss of performance due to vigilance issues (e.g., workload, boredom, attentional tunneling) by increasing the reliability of the alarm system. The "fuzzification" algorithm essentially converts input data to propositional statements and feeds them into a complex if-then rule set. The if-then rules are initially weighted based on expected and known alarm rates for a given system. As the fuzzy logic system actively monitors and logs true false alarms instead of interrupting the operator for every alarm, operator trust increases, resulting in a more reliable alarm system. Further, the operator trains the system by providing feedback on true alarms, causing the weights on the fuzzy logic formula to change over time, resulting in dynamic learning similar to that exhibited by the human operators. The overall effect of Liu and Su's fuzzy logic algorithm was increased alarm trust and a reduction in vigilance loss by the human supervisors. 
Larsson (2000) presents another method of alarm mitigation referred to as alarm sanitation. Unlike the software solutions of Liu and Su (2006) and Bock, Brotherton, Grabill, Gass \& Keller (2006) to attenuate or simply log nuisance alarms, Larsson present a framework for identifying and tuning the response thresholds for noisy alarms. All three processes result in higher trust by the human operator and therefore improved alarm sensitivity.

Alarm sanitation (i.e., management) is the process of using system logs and electrical signal characteristics of corresponding plant components to identify noisy alarms and retune their thresholds to bring the number of false alarms back to expected or acceptable limits. Larsson estimates that as much as $30 \%$ of alarms in a complex system like an NPP can benefit from alarm tuning. During the alarm tuning process, Larsson also recommended using system logs to identify alarms that never alert. Unresponsive alarms may need to be returned to their original thresholds or may simply be in need of repair but in either case are not contributing to plant operations and may even inhibit operator response along the lines of Gilson, Mouloua, Graft and McDonald (2001). Larsson does note that adding another alarm to a complex process like an NPP seems counterintuitive, but the improved system reliability will offset any costs incurred.

Smith, Howard and Foord (2003) present another tool to improve overall operator trust in the alarm system. They note that many alarms simply indicate the completion of a process, others may be alerting to the need for maintenance or because a component is offline while actively receiving maintenance, etc., and do not need the attention or action of the operator. They also note that a system as complex as a NPP has components made by different manufacturers, different countries, etc., and each has inherently different reliability thresholds. When combined into a system like an NPP, there's an overall loss of reliability due to the interaction of all of the different alarm thresholds, and some components may alert simply because of a different component's distinct alarm thresholds. In any case, the effect is loss of operator trust.

Smith et al. (2003) propose an alarm management method that uses system logs to identify noisy alarms as part of their design or due to systems interactions but that don't contribute to operations management. Once identified, noisy alarms that contribute no useful information for the operator can simply be logged instead of alerting and requiring a response. As with other alarm tuning methods, the result is fewer false alarms for the operator to manage and thus increased operator performance.

Smith et al. 2003 frame the need for alarm management as part of a quality assurance (QA) management process that they believe is lacking in NPP control rooms. In the typical QA process, system components and thresholds are subject to a schedule of periodic assessment, adjustment and re-assessment. A question forNPP administrators and owners is, why is alarm functioning not included in the plant's overall QA process? Part of management's poor control of alarm systems stems from conflicting business directives. Plant owners naturally seek the lowest operating costs, which includes going with the lowest bidder, combining new and legacy plant systems as a plant ages, and consolidation of departments and operator roles to reduce operating costs, but many of those decisions and actions also contribute to lower reliability. Smith et al. 
(2003) conclude that those are typical aspects of managing a complex industrial system like an NPP, but recommend that NPP owners and administrators compensate for the loss of reliability by instituting or improving QA mechanisms.

\section{Human operators in a complex, multi-alarm environment}

Meyer and Bitan (2002) examined the factors that contribute to Automation Bias - simply trusting that the alarm system knows what it is doing and reacting to every alarm as if valid, sometimes ignoring other information to the contrary. Building on ideas put forward in Meyer (2001), alarm compliance and alarm reliance are especially prominent phenomena for new operators but the influence of both fade as the operator gains experience. Compliance tends to be exhibited in hazard warning systems - the alarm sounds when something is wrong and the operator needs to do something to rectify the situation. Reliance refers to an operator's tendency to trust and rely on System OK messages, that is, they rely on the system's report that things are well (e.g., a green light or absence of an annunciator), often to the exclusion of contradictory or other information of concern.

Meyer (2001), found evidence that both compliance and reliance fade as the operator gains experience with the alarm system. Put simply, a single alarm becomes less important to the operator as his/her overall understanding of the system increases. That alone should not be surprising. However, they also found that experienced operators improved alarm reliability by how they maintained the system. Meyer \& Bitan (2002) found that better operators receive a lower number of alarm events precisely because they maintain the system within limits better than novice operators. Their preventative approach to system stability reduced both the frequency and the information value of the alarm, which in turn lead to higher overall system sensitivity.

The approach outlined above could be compared to the notion of cooking using the smoke detector. As one learns to cook, the detector goes off less often and you begin to ignore it because the cause is already known - burning food. However, once a certain amount of experience is gained, the alarm regains its information value because now that you no longer set it off by cooking, the alarm's information value returns to its designed function: detection of genuine fire.

Meyer (2004) further investigates and expands on compliance and reliance responses in dynamic warning systems. Meyers (2004) found that compliance doesn't change with experience but that reliance decreases as the operator learns, and that compliance was affected by distance or separation from main system indicators but that reliance was not.

Meyer considers his concepts of compliance and reliance analogous to errors of commission and omission (respectively) from cognitive psychology. A commission error refers to someone choosing the wrong course of action (answer to a test question) in the presence of information to the contrary. Someone who always complies with a warning signal is erring on the side of commission errors. An omission error occurs when someone fails to respond (answer a question). 
An operator who completely trusts 'system OK' indicators runs the risk of omitting or delaying a response due to his reliance on the alarm system.

Meyer (2004) presents the following framework to categorize the sources of variation that reduce alarm system performance from its theoretical performance to the performance achieved in the real world.

- Normative factors - characteristics of the system

○ Diagnostic factors - properties of the warning system and additional information available

○ Situational factors - costs and benefits for correct and incorrect (or absent) responses

- Task factors - characteristics of the task the operator is doing when the warning occurs

○ Task structure - number of system indicators, systems, and alarms monitored by the operator, time pressure, external pressure, other people observing, etc.

- Interface structure - how task information is displayed

- Operator-related factors - operator-specific characteristics unique to each task

- General - ability, training, risk strategy, skills, crisis performance

- System specific operator characteristics - characteristics specified by the task itself (e.g., type of industrial process being managed)

Bitan and Meyer (2007) examined reaction to alarms when working with a complex and ongoing schedule of activities by studying nurses in a medical intensive care unit. Medical alarms (e.g., heart and respiration monitors) have a high false alarm rate, as the cost of a missed alarm event can be quite high, possibly even life threatening. The authors note the similarity to an NPP control room, in that like ICU nurses; operators follow a schedule of routine monitoring, recording and adjusting system states while also responding to intermittent alarms. In essence, alarm response becomes a secondary vigilance task for an actively engaged operator. Bitan and Meyer feel that the view of the operator as actively engaged has more ecological validity than considering the operator as a passive responder who simply sits and waits for an alarm.

Extending the reliance-compliance distinction presented by Meyer (2001), the authors found partial support for both in the ICU. Bitan and Meyer (2007) found that the ICU nurses did rely on system ok indicators (i.e., green status lights), but never completely. The nurses always sampled the indicators in addition to monitoring for the alarm, above the rate indicated if they simply based their trust on probability matching. They also found compliance with hazard alarms (i.e., red alerts), but that the ICU nurses also 'oversampled' the indicators, showing that although they trusted the hazard alert, they did not trust them completely and sampled them more often than a probability-matching, trust-based estimate would predict. For both types of alarms, the authors concluded that the high cost of a missed alarm (i.e., potential patient decline or death) prevented the operators from ever completely trusting the alarm system. 


\section{Complex Alarm Environments}

Gilson, Mouloua, Graft, and McDonald (2001) examined the influence of nearby alarms on the response to an unreliable alarm to test the notion of Alarm Independence - the idea that operators perceive each alarm as a stochastic event. . Gilson et al. (2001) note that responding to more than one alarm forces the operator to diagnose more complex system processes and it becomes harder to prioritize responses as system interactions increase and begin to obscure the response space. A real world and worst case scenario of multiple alarms was Three Mile Island where an estimated 500 alarms went off at once In an extreme case like Three Mile Island, responding during a multi-alarm crisis becomes a signal-to-noise filtering task in a complex, noisy environment under time and pressure. "In the designers' well-meaning attempts to inform about everything, they informed about nothing" (p. 595).

In the lab, the question was one of how do multiple and increasing extraneous alarms influence an operator's response to a specific alarm. Initially, they found a linear relationship between the number of extraneous alarms and response to the primary and less than reliable alarm. The more alarms that sounded, the higher the participants' confidence in the target alarm. They also found the inverse, in that a panel of inactive alarms lowered the participants' confidence in the target alarm. Further examination found that the operators were responding to the proportion of ancillary alarms, not simply the increased number of alarms, and adjusting their confidence in the unreliable target alarm as a result.

Subsequent experiments tested the influence of a variety of nearby extraneous alarms with physical proximity, temporal proximity and cognitive proximity (i.e., alarms from related components of the primary alarm subsystem). For physical proximity, they found that the influence of ancillary alarms decreased with distance. For temporal proximity, they found that ancillary alarms had the greatest impact if they occurred around the same time as the target alarm, with the effect fading as the time span increases. Finally, they investigated the impact of cognitive proximity, defined as the impact on ancillary alarms from the same system components as the target alarm. For example, if the target alarm was system pressure, would other indicators related to pressure such as flow rate and temperature increase the operator's confidence in a less than reliable alarm? Gilson et al. (2001) found that there was an influence of cognitive proximity, but not as much as due to physical or temporal proximity. The authors conclude that both the additive and inhibitory influence of proximal alarms can be incorporated in display design and training to better shape operator response during multi-alarm scenarios.

Amaldi and Chellappah (2009) examined alarm integration issues that arise when adding a new, standalone alarm to an already complex operator environment using data obtained in a study of aircraft Anti Collision and Avoidance System (ACAS). ACAS is an onboard alarm system that actively queries nearby aircraft and determines their trajectories. ACAS was added to existing cockpits in the wake of a high profile air collision over Switzerland and is completely isolated from and independent of all other sensors, flight systems and the control tower. 
Amaldi and Chellappah (2009) reviewed several styles of safety design: Additive - the more alarms the better; Linearity - a modular approach that considers each module in isolation, without looking at interactions; and Limited Cognition designs that include features to support weaknesses in human perception and cognition (memory span, vigilance failure, lack of training, etc.).

They studied 3500 ACAS reports over Europe to determine whether the pilots treated the ACAS as a standalone warning system or they integrated the new alarm into the rest of the cockpit system. They found that the new alarm was not treated as a standalone system but integrated into other information sources available to the pilot. Due to design factors, however, they found that ACAS threw so many false alarms that it lowered overall operator performance by increasing operator workload while adding no useful information. The authors conclude that adding a separate alarm to an already complex alarm array can be beneficial if designed and integrated properly.

Otherwise, at some point adding more safety nets just tangles the nets and results in lower overall safety.

\section{Alarm Rates and Alarm Information}

Stanton, Harrison, Taylor-Burge and Porter (200o) studied the effect of alarm rate and the ratio of alarm to non-alarm information on the performance of laboratory participants. The authors contend that while alarm management efforts can reduce the total number of alarms, this reduction should not be viewed as the only measure of success. Success should be evaluated against multiple criteria including: time to diagnose, changes in mental workload, changes in the number of required control actions, successfulness of the control actions, the quality of diagnosis, output performance and detection rates. Responding to the wave of alarm reduction efforts, Stanton and his colleagues suggest that reducing the number of alarm can have a paradoxical effect on operators. They note that the reduction of redundant alarms can reduce an operator's awareness of the plant's state. Citing work by Sanquist and Fujita (1989), Stanton et al. report that reducing the number of alarms can actually increase, rather than decrease, workload.

Stanton and his colleagues used a simulated alarm display and secondary task and manipulated the rate of alarms, one alarm per second, one alarm every four seconds, and one alarm every eight seconds. Using an alarm list, the authors varied the proportion of alarms relative to non-alarm information across three levels: $2 \%, 6 \%$, and $10 \%$. In a between-subjects design, performance was measured using an index of detectability. Analysis of the resulting data revealed no significant effect of alarm proportion. Detectability, however, was significantly lower in the one alarm per second condition relative to the one alarm per four or eight second condition. The authors conclude that the ratio of alarm to non-alarm information is not as important as the rate of alarms. Increasing the alarm rate to one per second significantly decreases detectability. Alarm rates of one per four and eight seconds did not differ. According to the authors, the fact that varying the proportion of alarm information did not affect performance suggests that alarm management efforts (e.g., filtering) would not produce the expected benefit of increasing alarm detection. Based on this finding, or lack of thereof, the authors suggest that greater benefit would 
be achieved by focusing on reducing the alarm rate over the alarm content. It is not readily apparent from the study, however, how the authors would tease apart the confound between alarm rate and the alarm content proportion.

\section{Human Alarm Response Capabilities}

Industry and research alarm advocates have endeavored to define the number of alarms a human operator can manage. In the period of reviewed literature, two different approaches have been used: response modeling and empirical assessment.

Reising, Downs, and Bayn (2004) employed two separate methods in an effort to determine the time needed for a human to respond to alarms common in the processing industry. The authors generalized the Keystroke-Level Model (KLM) previously used in human-computer interaction research. Using KLM the authors decomposed the alarm response behavior into four subtasks: access condition, determine action, execute action, and determine effect. These tasks were further decomposed to identify the primitive operators which were then associated with time values. The second method involved a Markov transition analysis that examined the conditional probabilities of transitioning from one aspect of an alarm response to another aspect. These probabilities were used to create estimates of the time needed for an operator to respond to an alarm. The authors based the probabilities used in the estimates on the behavior of process plant operators who were completing an annual refresher course on a full-scope control room simulator.

The two methods produce dramatically different outcomes. Using KLM, the authors report that a response to a single alarm would require 3 minutes and 22 seconds. A flood of 10, 20, 30 simultaneous alarms would require 34,88 , and 150 minutes of response time, respectively. The Markov method produced short time estimates. Using this method, the authors showed that 49 seconds would be needed to respond to a single alarm. The authors note that this interval, 49 seconds, should be considered the maximum (performance ceiling) an operator can produce. Moreover, they were unable to determine if an operator could sustain this level of alarm response over a longer period of time, and were unable to assess how the level of alarm rationalization might affect this time estimate. They note that poorly designed alarm systems are likely to increase the predicted alarm response time. The authors conclude that the results support the EEMUA 191 benchmark alarm rate values of less than one alarm per 10 minutes (EEMUA, 2007).

Strobhar (2010) examined how many alarms \& messages an operator can handle over a given period of time. The article begins by questioning several oft quoted limits on the number of alarms an operator should be expected to handle as experimentally unverified and unnecessarily low. In the experiment reported, the authors found no difference in performance for slow alarm rates (up to 1 / minute) but that performance degraded as the alarm presentation rate approached 2 per minute. Although there were some methodological and generalizability questions raised by experimental characteristics, the authors are probably justified in their conclusion that the 
maximum alarm rate is operator and control room specific and the use of generalized alarm rates is of doubtful utility.

\section{Operators and Alarms in Analog and Digital Control Rooms}

Mumaw, Roth, Vicente \& Burns (2000) and Vicente, Roth \& Mumaw (2001) present the results of ethnographic studies of NPP operators in their natural environment with the specific goal of understanding operator behavior during normal plant operations. The earlier article lays the basis for using an ethnographic approach to study NPP control room performance and communications. The authors outline a clever method to bootstrap the validity of their observational methods by crosschecking individual observers against each other and against nonobserved NPP control room operators.

Mumaw, Roth, Vicente \& Burns (2000) found that NPP monitoring during normal operations was more than just passive vigilance. They found it to be a complex, cognitively challenging, continual process of active problem solving, much of which consisted of selecting salient information from a rich and dynamic information background. Mumaw et al. (200o) also found that NPP operators used much more information than what was presented on the display panels. Among the supplementary information NPP plant operators were observed to use were:

- Information from outgoing shift workers

- Formalized panel reviews and panel walkthroughs

- Reviews of long term performance data, sometimes going back weeks

- Reviews of system logs - both short term daily logs and long term status binders

- System diagnostic tests

- Alarm status and recent history

- Reports from field operators beyond the control room

- Field tours through the plant itself

Mumaw, Roth, Vicente \& Burns (2000) also observed some other characteristics specific to managing a complex industrial process like a nuclear power plant. The NPP contains tens of thousands of parts and sensors with differing reliability levels, all of which contribute dynamic changes in alarm reliability in the control room. For each and all of the plant specific problems, the operators have to learn which alarms can be ignored, adjusted or deactivated, adding substantially to the learning curve for a new operator at the NPP and adding to the mental workload of all operators.

Mumaw et al. (2000) noted that many alarm thresholds are not context-sensitive, causing them to alert due to acceptable status changes in related components. They also observed some alarms sound continually because the plant operates out of spec with the design but the alarms had not been updated. In some cases, multiple alarms were triggered by a single common cause, overrepresenting the importance of the malfunction itself. They found that some sensors had fixed thresholds but operated in dynamic operating ranges that caused them to alert when other normally operating systems moved in and out of their fixed threshold limits. The authors also 
observed that due to the reality of operating a system as complex as a NPP, many components can only be repaired when the plant is shut down. Thus, there were always broken units waiting for repair and sounding alarms.

Mumaw et al. (2000) conclude that as many as 50\% of alarms do not require operator interaction. If that is the case, the alarm pre-processing strategies described elsewhere in this review gain considerable value as a way to reduce the workload and increase the reliability of NPP operations.

Mumaw et al. (2000) noticed a number of display problems that hampered the reliability of the NPP control room. Ranging from simple mechanical failures of analog meters to missed opportunities to take advantage of human visual perception, most could have been addressed during design or simply repaired. For example, analog style meters wear out like any other mechanical device, but in a way that has implications for the NPP - when a meter 'dies' it often freezes the needle at the last reading instead of returning to zero. The effect is that it fails to become an emergent feature distinct from the meters all around it and may go undetected indefinitely. On the obverse, the change to CRT based displays brings many improvements to the control room, but at the cost of an emergent feature - the ability to scan all indicators at once to quickly ascertain the overall plant status.

Finally, Mumaw et al. (200o) documented a number of strategies developed by the operators themselves to maximize their performance. They saw a number of strategies to improve information extraction from the noisy background of the typical NPP control room, including enhancing key signals, documenting baselines and trends, and integrating certain ambient information into their decision making process (e.g., a rumbling noise each time a valve opens). The authors observed that some operators created new information to highlight specific processes or component activity, including the creation of new alarms, by adding new set points to existing displays or adding a second alarm trigger to indicate an increase from a steady state alarm. Operators were observed adjusting secondary alarm systems to report on primary systems without their own alarms (e.g., a component may lack a pressure gauge, but the pressure can be derived from the component's temperature and flow rate sensors).

Vicente, Roth and Mumaw (2001) follow up on Mumaw, Roth, Vicente \& Burns (2000) but in a new digital NPP control room. In general, they found that operators in the digital NPP control used the same information and strategies as operators in an analog control room, but used different behaviors to accomplish the same tasks. This seems reasonable since the underlying physical process and the human operators have not changed; only the displays are new.

Vicente et al. (2001) noted a number of control room differences beyond the simple substitution of digital for analog displays. They observed that digital control rooms group displays by reactor units then by subsystems, whereas the legacy control rooms grouped displays by function, then by reactor. The effect was to focus the operator on the overall condition of each reactor instead of the condition of a subsystem such as the overall plant pumping system. In the new NPP, they found that some of the CRTs were dedicated to specific systems; others could be shifted by the 
operator to serially monitor many subsystems by cycling through windows. Vicente et al. (2001) noted a benefit due to the hierarchical arrangement of the information in the digital control room, and found extensive use of operator customizable displays that including trend mapping, tracking for non-trended data, and other ways to adapt the system to the operator's preference.

In general, Vicente, Roth \& Mumaw (2001) found that the digital NPP control room had far fewer nuisance alarms, and thus, higher trust than the analog system, despite having approximately three times the number the alarms as legacy systems. They noted that the digital control room made much more diagnostic information available to operator and that the information design and presentation on the digital displays had advanced significantly. Digital control rooms were perceived (but not measured) to be quieter than analog control rooms. The observers believed that the layout of the new control room made it easier to echolocate alarms and operators had less chance of orienting on the wrong display during a multi-alarm crisis. They also noticed that the operators made fewer walkthroughs through the physical plant, instead relying on "screen walkthroughs" of the display screens and on cell phone contract with field workers in the physical plant.

Vicente et al. (2001) also found some design and performance issues carried over from the legacy control room to the digital and a new problem operator behavior specific to the digital control room. System complexity has increased greatly in the generation of plants with digital control rooms, resulting in a significant increase in the number of components and plant states to monitor, manage and maintain. The increased complexity requires operators to develop and use even more complex mental models, which were already strained in the older design. The authors noticed that while false alarms were greatly reduced, there were still many components that threw false alarms due to poor or absent context sensitivity. The effect was that the digital control room still requires that new operators face a steep learning curve as they discover which alarms are serious and which are nuisance alarms.

The switch from analog, room-wide displays to digital consoles caused a change in information seeking behavior. In the analog room, the operators could focus on any indicator simply by looking or walking around the control room. In the digital control room, instead of broad scanning, the operator has to serially page through windows displaying subsets of the information previous available at a glance. On the other hand, the operators became skilled at accessing only the information that they needed and the ability to customize the digital displays to operator preferences and to specific component subsystems of interest may compensate for the loss of general awareness associated with the analog control room.

The new class of operator behavior specific to the digital control room that may lead to performance decrements was termed the 'keyhole effect.' Essentially an extension of cognitive tunneling, Vicente et al. (2001) observed that when working under pressure, operators had a tendency to get keyholed in their work station, sometimes to the degree that they declined to seek accurate information available elsewhere, using proxy data or simply proceeding without information that might have been beneficial. 
Vicente et al. (2001) noticed a number of cognitive offloading techniques originally observed in analog control rooms, such as post-it notes, lists, adding or adjusting set points to processes to detect change in addition to above threshold conditions, etc. As mentioned above, they observed a number of new operator behaviors specific to working on digital consoles, such as ad hoc trend line analyses, signal enhancement, and construction of new displays and alarms on the fly to maximize understanding of processes not afforded by existing displays. Interestingly, the observers noticed the operators in digital control rooms made more use of printouts, in part to compensate for the loss of previously available, instantly visible system indicators in the windowbased CRT display environment.

\section{In situ NPP Operator Development}

Carvalho, Santos \& Vidal (2006) examined individual operator's development and use of proprietary procedures and cultural factors unique to each control room. Carvalho et al. (2006) note that complex control environments come with large sets of complex \& formal procedures that have been developed to minimize human error. However, it is also well known that experienced operators develop their own experience-based protocols. Carvalho et al. describe these protocols as "operators fill(ing) in the blanks and comply(ing) with the implied elements of the specified procedure" and Mumaw, Roth, Vicente \& Burns (200o) referred to as 'finishing the design.”

Carvalho et al. (2006) note that no matter how well designed a system, the operators who use it in the real world will find and compensate for or exploit design omissions as they move from novice to expert level users. They suggest that removing these operators or field developed protocols from an existing system would result in lower operating reliability. The authors suggest that these undocumented protocols are desirable - they're what the human brings to troubleshooting and problem solving that the machines don't know how to do yet - and highlight areas of the control system that need refinement while at the same time providing clear instruction on how to address the system's shortcomings.

But Carvalho et al. (2006) also note that operator innovation is a double edged sword. While field deviation from formal protocols constitutes the core of a quality assurance approach to system refinement, should a genuine crisis occur, especially one that results in damage, loss of operations, income or life, the subsequent investigations will inevitably focus on protocol deviations as one of the root causes of the incident. The authors cite a number of industrial accidents where human error (i.e., the use of informal protocols) was identified as contributing to the crisis (e.g., Three Mile Island).

Carvalho et al. (2006) also examined the culture in modern NPP control room as the knowledge, lingo, shared troubleshooting and crisis experiences, etc., of the operating team at a specific plant. They noted a number of team factors that should receive further investigation for possible inclusion into future operating protocols. Communications between shift changes, support of individual operators during active troubleshooting, documentation of field-developed protocols and workarounds, even shared knowledge and experience of normal plant operations (e.g., 
awareness of sounds, vibrations, etc.) are all part of the local culture. Informally transmitted to new operators in the form of lore or oral history, the authors recommend identifying and including control room culture and lore in formal training protocols.

\section{Simulating the NPP Operator}

Tran, Gertman, Dudenhoeffer, Boring \& Mecham (2007) present an enhancement to the current practice of manikin-based control room design software by adding certain known human perceptual and cognitive characteristics. They recharacterize the design process to include three modeling systems that need to be addressed: the environment, the manikin \& human perception and cognition. For example, they recommend that the manikins in the traditional design process be updated to include human characteristics such as useful field of vision, peripheral vision, memory span, cognitive tunneling and so on. Cognitive tunneling, for example, could be modeled by reducing the width of the manikin's field of vision during a simulated multi-alarm scenario so that only displays directly related to a system problem would be available for the manikin's inspection.

Yow, Walters, Plott, Laughery \& Persensky (2005) present methodology to use Discrete Event Simulations (DES) to model NPP control scenarios, test operator workload under extreme conditions, etc. DES models processes as a series of discrete events and can generate a system specific performance model against which human performance can be understood. The bulk of the article is on technical aspects of DES modeling, but the authors do conclude that using DES combined with human operator performance data is a valuable tool that can be applied to complex process management scenarios such as NPPs.

\section{Implications for Future NPP Control Rooms}

It would appear that portions of the US nuclear power industry has been spared the maturational pains experience in the processing or telecommunications industries. The slower transitions from analog to digital control systems has in some ways given the nuclear power industry the unique opportunity to learn critical lessons before moving headlong into distributed control systems. The value of these lessons, however, should not be ignored. In comparison, the control rooms of the 1980 s would be considered quiet in contrast to many contemporary control rooms in today's process industry. Failing to heed the lessons learned in industries with DCS, NPP upgrades could plunge a control room into a foreign world tyrannized by ubiquitous alarms. Upgrades should be navigated carefully with one eye on the demonstrated successes of history and another on the opportunities to enhance plant performance, better manage operator workload, and promote increased reliability through advanced digitally-based systems. Although many lessons have been learned, many the hard way, questions remain. On the heels of a concerted effort to upgrade the aging control rooms in many US NPPs, it is an opportune time to address these questions knowing that the answers they produce will likely affect the next 20 to 30 years of plant operation. 


\section{References}

Advanced Alarm Management (August, 2009). Advanced alarm management - value added SCADA technology. Vector, 43-44.

Aizpurúa, O., Galán, R., \& Jiménez, A. (2008). A new cognitive-based massive alarm management system in electrical power administration. 7th International Caribbean Conference on Devices, Circuits and Systems, Mexico, 2008. Retrieved from:

http://ieeexplore.ieee.org/xpl/freeabs_all.jsp?arnumber $=4542607$.

Alford, J.S., Kindervater, J., \& Stankovich, R. (2005). Alarm Management for Regulated Industries. Chemical Engineering Progress. Retrieved from:

http://findarticles.com/p/articles/mi_qa5350/is_200504/ai_n21370379/.

Amaldi, P., \& Chellappah, A. (2009). The integration of alarm device into socio-technical systems: The case of an onboard alert device (ACAS). 4th IET International Conference on Systems Safety 2009. Incorporating the SaRS Annual Conference, 1 - 7. link

Angelucci, D., Di Paolo, S., \& Tarantino, L. (2009). Designing a glanceable peripheral display for severity-based multiple alarm notification. HSI 'og. 2nd Conference on Human System Interactions, May 2009, 342 - 346. link

International Society for Automation. (2009). ANSI/ISA-18.2-2009 Management of Alarm Systems for the Process Industries. link

Bitan, Y., \& Meyer, J. (2007). Self-initiated and respondent actions in a simulated control task. Ergonomics, 50(5), $763-788$. link

Bliss, J. P. (2003). Investigation of alarm-related accidents and incidents in aviation. The International Journal of Aviation Psychology, 13(3), 249 - 268.

Bliss, J. P., \& Dunn, M. C. (200o). Behavioral implications of alarm mistrust as a function of task workload. Ergonomics, 43(9), 1283-300. link

Bliss, J. P., Gilson, R., \& Deaton, J. (1995b). Human probability matching behaviour in response to alarms of variable reliability. Ergonomics, 36, $2300-2312$. link

Bliss, J. P., Jeans, S. M., \& Prioux, H. J. (1996). Dual-task performance as a function of individual alarm validity and alarm system reliability information. Proceedings of the Human Factors and Ergonomics Society 4oth Annual Meeting, 1237-1241. 
Bock, J. R., Brotherton, T., Grabill, P., Gass, D., \& Keller, J. A. (2006). On false alarm mitigation. Aerospace Conference, 2006 IEEE, IEEEAC paper \#1433, v1. Retrieved from:

http://ieeexplore.ieee.org/xpl/freeabs all.jsp?arnumber=1656101.

Bransby, M. L. (2000). Best practice in alarm management. Control of Railways - The Human Challenge, $8,1-4$. link

Breznitz, S. (1983). Cry-wolf: The psychology of false alarms. L. Erlbaum Associates: Mahwah, NJ.

Brooks, R., \& Wilson, J. (2003). Geometry Unifies Process Control, Production Control \& Alarm Management. Retrieved from: http://www.automation.com/resources-tools/articles-whitepapers/process-control-process-monitoring/geometry-unifies-process-control-productioncontrol-alarm-management.

Brooks, R., Thorpe, R., \& Wilson J. (2004). A new method for defining and managing process alarms and for correcting process operation when an alarm occurs. J Hazard Mater, 115(1), 169-174. Link

Burt, J. L., Bartolome, D. S., Burdette, D. W., \& Comstock, J. R. (1995). A psychophysiological evaluation of the perceived urgency of auditory warning signals. Ergonomics, 38(11), 2327-2340. link

Bustamante, E. A., Bliss, J. P., \& Anderson, B. L. (2007). Effects of varying the threshold of alarm systems and workload on human performance. Ergonomics, 5o(7), 1127-1147. link

Carvalho P. V. R, Santos, I. L., \& Vidal, M. C. (2006). Safety implications of cultural and cognitive issues in nuclear power plant operation. Applied Ergonomics, 37(2), 211-223. link

Carvalho, P. V. R., Santos, I. L., Gomes, J. O., Borges, M. R. S, \& Guerlain, S. (20o8). Human factors approach for evaluation and redesign of human-system interfaces of a nuclear power plant simulator. Displays, 29(3), 273-284. link

Chisholm, S. \& Romascanu, D. (2004). Alarm Management Information Base (MIB). Retrieved from: http://tools.ietf.org/html/rfc3877.

Cullen, L. (2007). Human factors integration - Bridging the gap between system designers and end-users: A case study. Safety Science, 45(5), 621-629. Link

Cummings, M. L., \& Guerlain, S. (2007). Developing Operator Capacity Estimates for Supervisory Control of Autonomous Vehicles. The Journal of the Human Factors and Ergonomics Society, 49(1), 1-15. link

Diamond, K. T., \& Dhalla, N. (2004). Best Practices in Alarm Management, Experience from the Field, unpublished manuscript. Matrikon, Inc. 
Dunn, D. G., \& Sands, N. P. (2005a). Alarm systems standards important. InTech. Retrieved from: http://www.isa.org/InTechTemplate.cfm?Section=Safety2\&template=/ContentManagement/Cont entDisplay.cfm\&ContentID=52994.

Dunn, D. G., \& Sands, N. P. (2005b). ISA-SP18 - Alarm Systems Management and Design Guide. ISA EXPO 2005, 25-27 October 2005, McCormick Place Lakeside Center, Chicago, Illinois. link

EEMUA, Engineering Equipment and Materials Users' Association. (2007). Alarm Systems - A Guide to Design, Management and Procurement, Publication 191, 2nd Edition. EEMUA: London, UK. link

EPRI, Electric Power Research Institute. (2003). Alarm Processing Methods: Improving Alarm Management in Nuclear Power Plant Control Rooms, EPRI 1003662, Palo Alto, CA.

EPRI, Electric Power Research Institute. (2005) Advanced Control Room Alarm System: Requirements and Implementation Guidance. EPRI report 1010076, Palo Alto, CA.

Errington, J., Reising, D. V., \& Burns, C. (2009). ASM Consortium Guidelines Effective Alarm Management Practice 2009. ASM Consortium: Phoenix, AZ. link

Foong, O. M., Sulaiman, S., Rambli, D. R. A., \& Abdullah, S. (2009). ALAP: Alarm Prioritization System for Oil Refinery. World Congress Engineering and Computer Science (WCECS 2009), October, 2009. link

Gaertner, D. (2007). Bringing Nuisance Alarms Under Control. Control Engineering, March 2007, $10-11$ link

Geng, Z., Zhu, Q., \& Gu, X. (2005). A fuzzy clustering-ranking algorithm and its application for alarm operating optimization in chemical processing. Process Safety Progress, 24(1), 66-75. link

Gilson, R. D., Mouloua, M., Graft, A. S., \& McDonald, D. P. (2001). Behavioral influences of proximal alarms. Human Factors, 43(4), 595-610. link

Goble, G., \& Stauffer, T. (2007). Avoid unplanned downtime from alarm overload, use top techniques to improve alarm management. Intech, Janaury 2007, $42-46$. link

Grosdidier, P., Connor, B., Hollifield, B., \& Kulkarni, S. (2003). A path forward to DCS alarm management. Hydrocarbon Processing, November 2003, 59-64. link

Haas, E. C., \& Casali, J. G. (1995). Perceived urgency of and response time to multi-tone and frequency-modulated warning signals in broadband noise. Ergonomics, 38, 2313-2326. link

Haas, E. C. \& Edworthy, J. (1996). Designing urgency into auditory warnings using pitch, speed and loudness. Computing and Control Engineering Journal, August, 193-8. link 
Hallbert, B. P., Persensky, J. J., Smidts, C., Aldemir, T., \& Naser, J. (2009). Report from the light water reactor sustainability workshop on advanced instrumentation, information, and control systems and human-system interface technology. Idaho National Laboratory.

Hatch, D., \& Stauffer, T. (2009). Operators on alert - Operator response, alarm standards, protection layers keys to safe plants. Intech, September 2009. Retrieved from:

http://www.isa.org/InTechTemplate.cfm?template=/ContentManagement/ContentDisplay.cfm\& ContentID $=78986$

Health \& Safety Executive. (200o). HSE Information Sheet: Better Alarm Handling. Retrieved from: http://www.hse.gov.uk/pubns/chis6.pdf.

Hellier, E., \& Edworthy, J. (1999). On using psychophysical techniques to achieve urgency mapping in auditory warnings. Applied ergonomics, 30(2), 167-71. link

Hollender, M. \& Beuthel, C. (2007). Intelligent Alarming - Effective alarm management improves safety, fault diagnoses and quality control. ABB Review, January 2007, 20-23. Link

Hollifield, B., \& Habibi, E. (2006). The Alarm Management Handbook - Second Edition: A Comprehensive Guide, PAS: Houston, TX. link

Huang, F,. Hwang, S., Yenn, T., Yu, Y., Hsu, C., \& Huang, H. (2006). Evaluation and comparison of alarm reset modes in advanced control room of nuclear power plants. Safety Science, 44(10), 935946. link

Huang, F. H., Lee, Y. L., Hwang, S. L., Yenn, T. C., Yu, Y. C., Hsu, C. C., \& Huang, H. W. (2007). Experimental evaluation of human-system interaction on alarm design. Nuclear Engineer and Design, 237, 308-315.

Hwang, S.L., Lin, J. T., Liang, G. F., Yau, Y. J, Yenn, T. C., \& Hsu, C. C. (20o8). Application control chart concepts of designing a pre-alarm system in the nuclear power plant control room. Nuclear Engineering and Design, 238(12), 3522 - 3527.

Jang, G., Keum, J., Park, H., \& Kim, Y. K. (2008). Active Alarm Processing in a Nuclear Power Plant. IEEE Symposium on Advanced Management of Information for Globalized Enterprises, 2008. Retrieved from: http://ieeexplore.ieee.org/Xplore/login.jsp?url=http\%3A\%2F\%2Fieeexplore.ieee.org\%2Fiel5\%2F47 21441\%2F4721442\%2F04721520.pdf\%3Farnumber\%3D4721520\&authDecision=-203.

Jang, G., Seong, D., Keum, J., Park, H., \& Kim, Y. K. (2008). The design characteristics of an advanced alarm system for SMART. Annals of Nuclear Energy 35(6), 1006-1015. 
Jukić, O., Halusek, V., \& Špoljarć, M. (2009). Low-level alarm filtration based on alarm classification. $51^{\text {st }}$ International Symposium ELMAR-2009, Zadar, Croatia, September 2009, 143 146. link

Kerstholt, J. H., \& Passenier, P. O. (2000). Fault management in supervisory control: the effect of false alarms and support. Ergonomics, 43(9), 1371-1389.

Kettschau, H. J., Bruck, S., \& Schefczik, P. (2002). LUCAS - an expert system for intelligent fault management and alarm correlation. Network Operations and Management Symposium, 2002, 903 -905. link

Lambert-Torres, G., Fonseca, E. F., Coutinho, M. P., \& Rossi, R. (2006). Intelligent Alarm Processing. International Conference on Power System Technology, PowerCon 2006, 1-6. link

Larraz, R. (2007). Probabilistic alarm management - A procedure using Markov chains provides insights based on HAZOP report information. Hydrocarbon Processing, October 1, 2007, 47 -51. link

Larsson, J. E., (200o). Simple Methods for Alarm Sanitation. In Proceedings of the IFAC Symposium on Artificial Intelligence in Real-Time Control, Budapest, Hungary.

Larsson, J. E., Öhman, B., Calzada, A., \& DeBor, J. (2006a). New Solutions for Alarm Problems. Published in the Proceedings of the 5 th Topical Meeting on Nuclear Plant Instrumentation, Control, and Human Interface Technology, Albuquerque, New Mexico, 2006. Retrieved from: http://www.goalart.com/publications/2006-NPIC-HMIT-Larsson-New-Solutions.pdf.

Larsson, J. E., Öhman, B., Calzada, A., Nihlwing, C., Jokstad, H., Kristiansen, L. I., Kvalem, J., \& Lind, M. (2006b). A Revival of the Alarm System: Making the Alarm List Useful During Incidents. Published in the Proceedings of the 5th Topical Meeting on Nuclear Plant Instrumentation, Control, and Human Interface Technology, Albuquerque, New Mexico, 20o6. Retrieved from: http://www.goalart.com/publications/2006-NPIC-HMIT-Larsson-Revival-Alarm-System.pdf.

Larsson, J. E., Öhman, B., Nihlwing, C., Jokstad, H., Kristianssen, L.I., \& Kvalem, J. (2005). Alarm reduction and root cause analysis for nuclear power plant control rooms. Enlarged Halden Program Group Meeting, 2005, Lillehammer, Norway. Retrieved from: http://www.dtu.dk/centre/cet/English/research/publications.aspx?lg=showcommon\&id=223867.

Liu, C., \& Su, K. (2006). A fuzzy logical vigilance alarm system for improving situation awareness and trust in supervisory control. Human Factors and Ergonomics in Manufacturing E Service Industries, 16(4), 409-426. link

Martinez, M. J. (2008). A three-point approach to effective alarm management. Plant Engineering, 62(12), 57 - 58. link 
Marvin, M., \& Eng, P. (2005). Alarm Management Blunders: Avoiding 12 Costly Mistakes. . Matrikon Inc, Canada. Retrieved from: http://www.plant-

maintenance.com/articles/AlarmManagement.pdf.

Meyer, J. (2001). Effects of warning validity and proximity on responses to warnings. Human Factors, 43(4), 563-572. link

Meyer, J. (2004). Conceptual Issues in the Study of Dynamic Hazard Warnings. The Journal of the Human Factors and Ergonomics Society, 46(2), 196-204. link

Meyer, J., \& Bitan, Y. (2002). Why better operators receive worse warnings. Human Factors, 44(3), 343-353. link

Momtahan, K., Hetu, R., \& Tansley, B. (1993) Audibility and identification of auditory alarms in the operating room and intensive care unit. Ergonomics, 36, 1159-117. link

Mostia Jr., W. L. (2005). How to perform alarm rationalization. Retrieved from:

http://www.controlglobal.com/articles/2005/320.html.

Mumaw, R. J., Roth, E. M., Vicente, K. J., \& Burns, C. M. (2000). There Is More to Monitoring a Nuclear Power Plant than Meets the Eye. Human Factors and Ergonomics Society Spring 200o, 42(1) 36-55. link

Nabeshima, K., Suzudo, T., Ohno, T., \& Kudo, K. (2002). Nuclear reactor monitoring with the combination of neural network and expert system. Mathematics and Computers in Simulation, 6o(3), 233-244. link

Nachreiner, F., Nickel, P., \& Meyer, I. (2006). Human factors in process control systems: The design of human-machine interfaces. Safety Science, 44(1), 5-26. Link

Norros, L., \& Nuutinen, M. (2005). Performance-based usability evaluation of a safety information and alarm system. International Journal of Human-Computer Studies, 63(3), 328-361. link

O Brien, L. (2008). Technology has created an alarm management crisis: Here's what needs to be done to solve the problem. Hydrocarbon Processing, 87(4), 123-125. link

O'Hara, J. M., Brown, W. S., Hallbert, B., Skraning, G., Persensky, J. J., Wachtel, J. (20oo). The Effects of Alarm Display, Processing, and Availability on Crew Performance. (NUREG/CR-6691). U.S. Nuclear Regulatory Commission: Washington, DC.

Pai, P. (2008). Alarm management life cycle provides process insight. Plant Engineering, April 2008, $53-55$. link 
Parasuraman, R., \& Masalonis, A. J. (2000). Designing Automated Alerting Systems: Standard and Fuzzy Signal Detection Theory and Bayesian Analysis. Human Factors and Ergonomics Society Annual Meeting Proceedings, Proceedings 3-Aerospace Systems, 9-12. link

Peryer, G., Noyes, J., Pleydell-Pearce, K., \& Lieven, N. (2005). Auditory alert characteristics: A survey of pilot views. The International Journal of Aviation Psychology, 15(3), 233 - 250. link

Project (3GPP). (2009). 3rd Generation Partnership Project; Technical Specification Group Services and System Aspects; Telecommunication management; Fault Management; Part 1: $3 \mathrm{G}$ fault management requirements (Release 9). Retrieved from:

http://www.quintillion.co.jp/3GPP/Specs/32111-1-90o.pdf.

Reising, D. C., Downs, J., \& Bayn, D. (2004). Human performance models for response to alarm notifications in the process industries: An industrial case study. In Proceedings of the Human Factors and Ergonomics Society 48th Annual Meeting (pp. 1189-1193). Santa Monica, CA: Human Factors and Ergonomics Society.

Reising, D. V. C., \& Montgomery, T. (2005). Achieving Effective Alarm System Performance: Results of ASMÒ Consortium Benchmarking against the EEMUA Guide for Alarm Systems. Proceedings of the 2oth Annual CCPS International Conference, Atlanta, GA, 11-13 April 2005. Retrieved from:

http://www.applyhcs.com/publications/interface_design/EffectiveAlarmSystemPerformance_CCP So5.pdf.

Sanquist, T. F. \& Fujita, Y. (1989). Protocol analysis and action classification in the evaluation of an advanced annunciator system design. Proceedings of the Human Factors Society 33rd Annual Meeting. October 16-2o, Denver, Colorado, 1064-1067. link

Shahriari, M., Shee, A., \& Örtengren, R. (2006). The development of critical criteria to improve the alarm system in the process industry. Human Factors and Ergonomics in Manufacturing \& Service Industries, 16, 321-337. Link

Six Sigma (February, 2008). Six Sigma improves alarm management. Control Magazine. Retrieved from: http://www.controlglobal.com

Six Sigma( March, 2008). Six Sigma improves alarm management: Part 2. Control Magazine. Retrieved from: http://www.controlglobal.com

Smith, W. H., Howard, C. R., \& Foord, A. G. (2003). Alarms Management - Priority, Floods, Tears or Gain? Retrieved from: http://4-

sightconsulting.co.uk/Current Papers/Alarms Management/Alarms Paper.pdf

Srinivasan, R, Liu, J, Lim, KW, Tan, KC \& Ho, WK. (2004). Intelligent Alarm Management in a Petroleum Refinery, Hydrocarbon Processing, November 2004, 47-53. 
Stanton, N. A., Harrison, D. J., Taylor-Burge, K. L., \& Porter, L. J. (2000). Sorting the Wheat from the Chaff: A Study of the Detection of Alarms. Cognition, Technology E Work, 2(3), 134-141. link

Strobhar, D. A. (2010). Operator performance as a function of alarm rate and interface design. WBF 2010 Conference, Austin, TX.

Swets, J. A. (1996). Signal detection theory and ROC analysis in psychology and diagnostics: Collected papers. L. Erlbaum Associates: Mahwah, NJ.

Szudajski, T., \& Hull, M. (2007). Reducing false alarms boosts efficiency: alarm management lets operators concentrate on running the plant without compromising their ability to respond to serious problems. Power Engineering, July 2007, 32 - 36. link

Tanner, R., Gould, J., Turner, R. and Atkinson T. (2005). Keeping the peace (and quiet).

ISA InTech, September 2005.

Thackray, R. I., \& Touchstone, R. M. (1970). Recovery of motor performance following startle. Perceptual and Motor Skills, 30, 279 - 292. link

Thunberg, A. \& Osvalder, A. L. (2007). What constitutes a well-designed alarm system? Human Factors and Power Plants and HPRCT 13th Annual Meeting, 2007 IEEE 8th, 85-91. link

Tran, T. Q., Gertman, D. I., Dudenhoeffer, D. D., Boring, R. L., \& Mecham, A. R. (2007). Cognitive virtualization: Combining cognitive models and virtual environments. Official Proceedings of the Joint 8th IEEE Conference on Human Factors and Power Plants and the 13th Annual Workshop on Human Performance/Root Cause/Trending/Operating Experience/Self Assessment, 195-200.

Traub, P., \& Hudson, R. (2007). Alarm Management Strategies on Ships Bridges and Railway Control Rooms, A Comparison of Approaches and Solutions. Human Factors in Ship Design, Safety and Operation, London, UK. link

Tuszynski , J., Larsson, J. E., \& Nihlwing, C. (2002). A Pilot Project on Alarm Reduction and Presentation Based on Multilevel Flow Models. The Proceedings of the Enlarged Halden Programme Group Meeting, HPR-358, Storefjell, Gol, Norway, 2002. Retrieved from: http://www.goalart.com/publications/2002-Halden-JT.pdf.

Tyler, R. R., Shilling, R. D., \& Gilson, R. D. (1995). False alarms in naval aircraft: a review of Naval Safety Center mishap data (Special Report 95-003). Orlando, FL: Naval Air Warfare Center Training Systems Division.

U. S. Nuclear Regulatory Commission. (200o). Advanced Alarm Systems: Revision of Guidance and Its Technical Basis (NUREG-6684). Washington, DC. link

U. S. Nuclear Regulatory Commission. (2002). Human-System Interface Design Review Guidelines (NUREG-070o). Washington, DC. link

60 References | Benchmark Research \& Safety, Inc. 
Varga, T., Szeifert, F., \& Abonyi, J. (2010). Process Models and Data Mining Techniques in Determination and Characterization of Safe Operating Regimes. Applied Process Solution Forum May 26-27, 2010,

Balatonfüred, Hungary. link

Vicente, K. J., Roth, E. M., \& Mumaw, R. J. (2001). How do operators monitor a complex, dynamic work domain? The impact of control room technology. International Journal of Human-

Computer Studies, 54(6), 831-856. link

Wallin, S. (2009). Chasing a definition of "alarm." Journal of Network and

Systems Management, 17(4)457-481. link

Wilmarth, T. (2010). Alarm management work process. 2010 AIChE and EPC Spring National Meeting, San Antonio, TX.

Yow, A., Walters, B., Plott, B., Laughery, R. \& Persensky, J. (2005). Predicting nuclear power-plant operator performance using discrete event simulation. Cognition, Technology \& Work, 7(1), 29-35. $\underline{\text { link }}$

Zupan, J., \& Medhi, D. (2003). An alarm management approach in the management of multilayered networks. IP Operations and Management, 2003. (IPOM 2003). 3rd IEEE Workshop, 77 84. link

Project (3GPP). (2009). 3rd Generation Partnership Project; Technical Specification Group Services and System Aspects; Telecommunication management; Fault Management; Part 1: $3 \mathrm{G}$ fault management requirements (Release 9). Retrieved from:

http://www.quintillion.co.jp/3GPP/Specs/32111-1-900.pdf. 